\title{
Rosana Raele
}

\author{
Associação da relação cintura-estatura (RCE) com a presença de \\ aterosclerose subclínica mensurada pelo escore de cálcio coronariano
}

(CAC) e pela espessura íntima média da carótida (EIMC)

Dissertação apresentada à Faculdade de Medicina da Universidade de São Paulo para obtenção do título de Mestre em Ciências

Programa de Ciências Médicas

Área de Concentração: Educação e Saúde

Orientadora: Profa. Dra. Isabela Judith Martins Benseñor

\section{São Paulo}


Dados Internacionais de Catalogação na Publicação (CIP)

Preparada pela Biblioteca da

Faculdade de Medicina da Universidade de São Paulo

Creprodução autorizada pelo autor

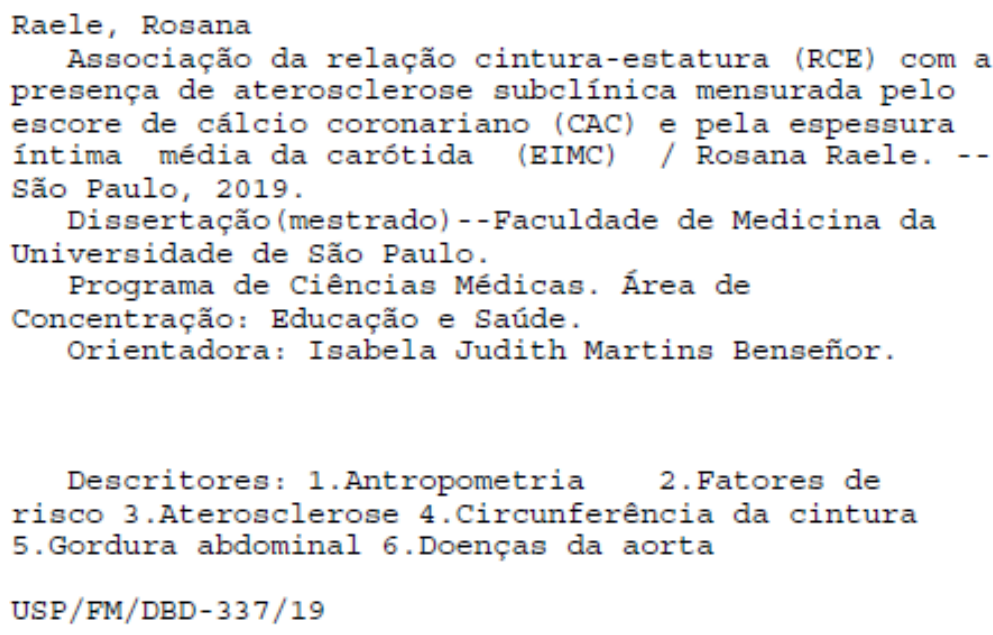

Responsável: Erinalva da Conceição Batista, CRB-8 6755 


\section{DEDICATÓRIA}

"Dedico este trabalho a meu pai João Raele (in memorian) e a minha mãe Dirce Raele (in memorian) mesmo distantes de meus olhos permanecem no meu caminho, transformando a saudade em luz para minha trajetória profissional e pessoal". 


\section{AGRADECIMENTOS}

A Deus, sobretudo, iluminando sempre a minha vida.

A minha querida família, pelo apoio, carinho e compreensão sempre.

A minha irmã Rosely, compreendendo meus momentos de dedicação a este trabalho.

A meu companheiro Beto, sempre com suas palavras de fortalecimento e incentivo para continuidade na realização de meu sonho.

A todos os meus colegas que sempre estiveram do meu lado com pensamentos positivos nesta fase de vida tão importante para mim.

A minha orientadora Isabela Judith Martins Benseñor pela dedicação e paciência na minha orientação.

Aos membros da banca de qualificação, os professores doutores: Bianca de Almeida-Pittitto, Claudia Kimie Suemoto e Itamar de Souza Santos com toda contribuição enriquecedora para meu trabalho.

A bibliotecária Erinalva que me auxiliou no momento final de meu trabalho com muita dedicação e paciência.

Aos participantes do ELSA-Brasil, com a valiosa contribuição para a comunidade científica. 


\section{SUMÁRIO}

Lista de Tabelas

Lista de Figuras

Lista de Abreviaturas e Siglas

Resumo

Abstract

1 INTRODUÇÃO .......................................................................................................... 13

1.1 Importância das Doenças Cardiovasculares ........................................................ 13

1.2 Doenças cardiovasculares no Brasil ....................................................................... 13

1.3 Obesidade Mundial e no Brasil .......................................................................... 15

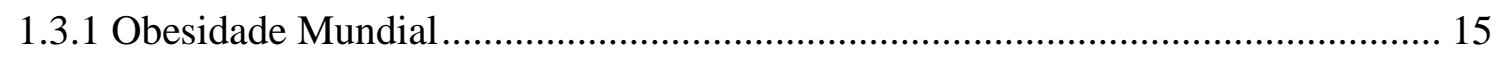

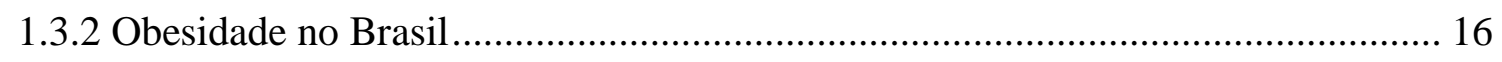

1.4 Obesidade e Risco Cardiovascular........................................................................... 17

1.5 Medidas Antropométricas na Avaliação da Obesidade .................................... 20

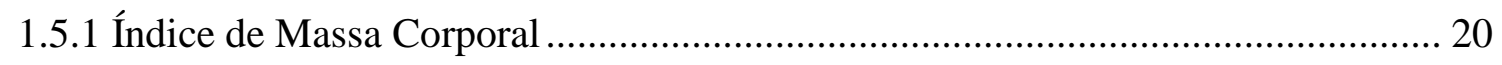

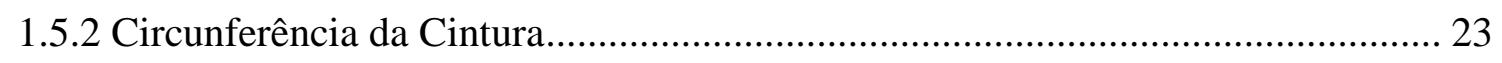

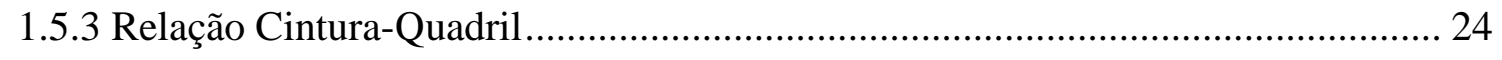

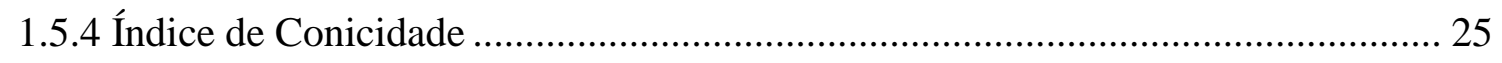

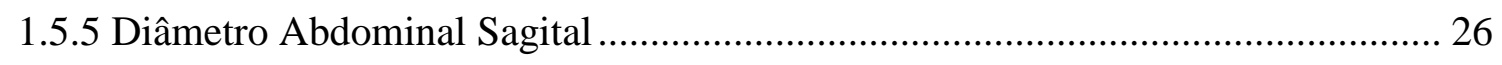

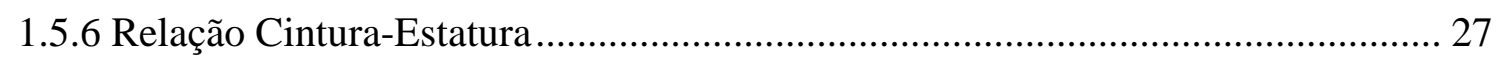

1.6 Aterosclerose Subclínica ................................................................................... 32

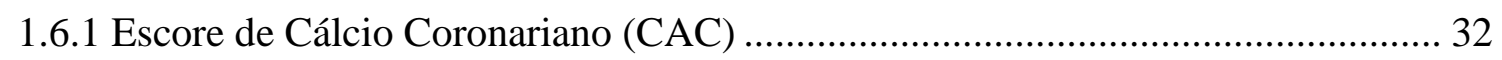

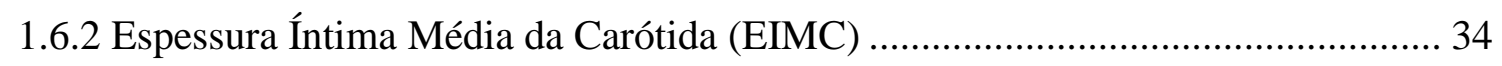

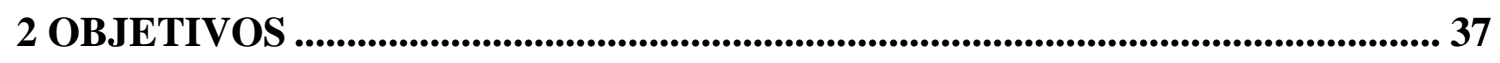

2.1 Objetivo Principal ................................................................................... 37

2.2 Objetivos Secundários............................................................................................ 37

3 HIPÓTESE............................................................................................................ 38

4 MÉTODOS.................................................................................................................. 39

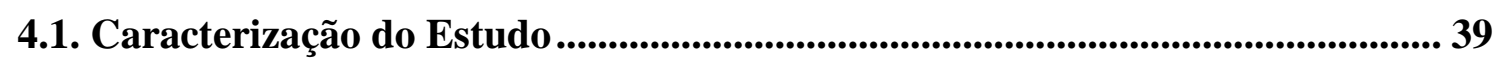

4.2 Aspectos Éticos da Pesquisa ........................................................................... 40 
4.3 Coleta de dados ............................................................................................................................. 40

4.4 Medidas antropométricas ............................................................................................... 41

4.5 Medição de Aterosclerose Subclínica............................................................................ 42

4.5.1 Escore de Cálcio Coronariano (CAC) …............................................................... 42

4.5.2 Espessura de íntima-média de carótida (EIMC) .................................................. 42

4.6 Outras variáveis de interesse ...................................................................................... 43

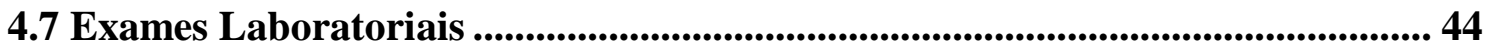

4.8 Critérios de Exclusão ........................................................................................... 44

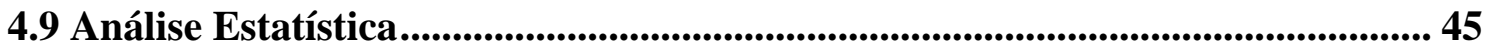

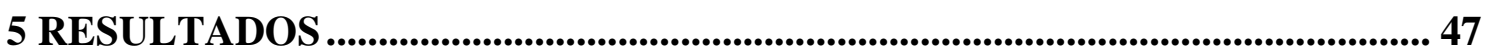

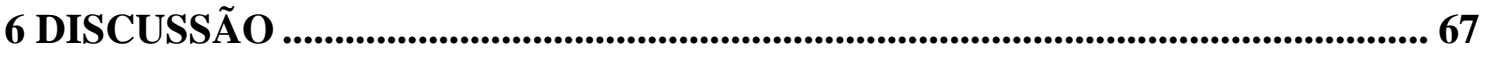

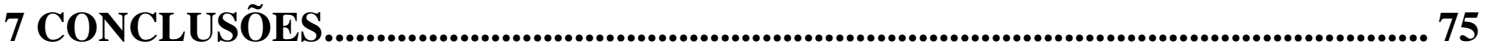

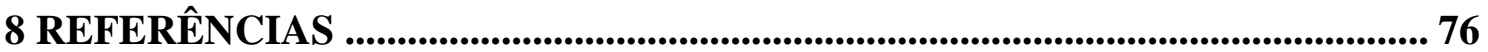




\section{LISTA DE FIGURAS}

Figura 1 - Maior risco de doenças cardiovasculares com aumento no índice de massa corporal 18

Figura 2 - Classificação Internacional de Obesidade segundo a Organização Mundial da Saúde 21

Figura 3 - Localização da medida da circunferência da cintura 24

Figura 4 - Medida do Diâmetro Sagital 27

Figura 5 - Fluxograma do Critério de Seleção da Amostra 48

Figura 6 - Presença de $\mathrm{CAC}>0$ nos grupos divididos conforme os quintis de RCE ..... 51

Figura 7 - Presença de CAC>100 nos grupos divididos conforme os quintis de RCE. 52

Figura 8 - Presença de EIMC>75 nos grupos divididos conforme os quintis de RCE.

ANOVA, análise de variância 52 


\section{LISTA DE TABELAS}

Tabela 1 - Características sociodemográficas da amostra ....................................... 49

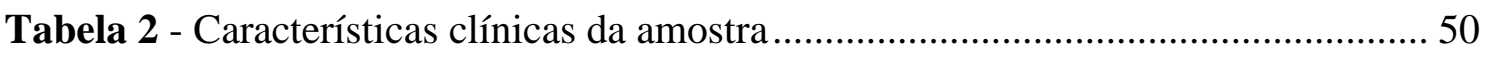

Tabela 3 - Características sociodemográficas da amostra no sexo masculino ............... 54

Tabela 4 - Características clínicas da amostra no sexo masculino .............................. 55

Tabela 5 - Características sociodemográficas da amostra no Sexo Feminino................ 57

Tabela 6 - Características clínicas da amostra no Sexo Feminino................................. 58

Tabela 7 - Razões de Chances (com intervalo de confiança de 95\%) da Associação dos

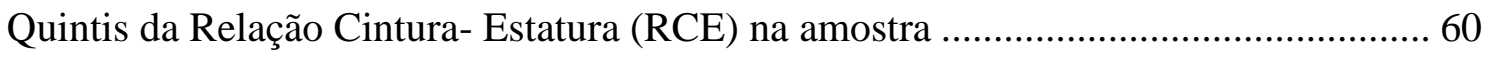

Tabela 8 - Razões de Chances (com intervalo de confiança de 95\%) da Associação dos Quintis da Relação Cintura- Estatura (RCE) com a presença de CAC na amostra no

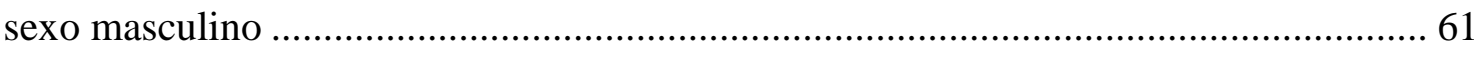

Tabela 9 - . Razões de Chances (com intervalo de confiança de 95\%) da Associação dos Quintis da Relação Cintura- Estatura (RCE) com a presença de CAC na amostra no sexo feminino

Tabela 10 - Razões de Chances e efeitos (com intervalo de confiança de 95\%) dos Quintis da Relação Cintura- Estatura (RCE) sobre EIMC

Tabela 11 - Razões de Chances e efeitos (com intervalo de confiança de 95\%) dos Quintis da Relação Cintura- Estatura (RCE) sobre EIMC, no sexo masculino 65

Tabela 12 - Razões de Chances e efeitos (com intervalo de confiança de 95\%) dos Quintis da Relação Cintura- Estatura (RCE) sobre EIMC, no sexo feminino 66 


\section{LISTA DE ABREVIATURAS E SIGLAS}

DP - Desvio Padrão

CC - Circunferência da Cintura

DAS - Diâmetro Abdominal Sagital

DCV - Doença Cardiovascular

EIMC - Espessura Íntima Média da Carótida

HA - Hipertensão Arterial

HDL - High Density Lipoprotein (Lipoproteína de Alta Densidade)

IBGE - Instituto Brasileiro de Geografia e Estatística

IC 95\% - Intervalo de Confiança de 95\%

ICO - Índice de Conicidade

IMC - Índice de Massa Corporal

$\mathrm{Kg} / \mathrm{m}^{2-}$ quilograma por metro quadrado

LDL - Low Density Lipoprotein (Lipoproteina de Baixa Densidade)

$\mu \mathrm{m}$ - micrômetro

$\mathrm{mm} / \mathrm{dL}$ - miligramas por decilitro

mm Hg - milímetros de mercúrio

OMS - Organização Mundial de Saúde

\% GC - Porcentagem de Gordura Corporal

PAD - Pressão Arterial Diastólica

PAS - Pressão Arterial Sistólica

RCE - Relação Cintura-Estatura

RCQ - Relação Cintura- Quadril

WHO - World Health Organization 


\section{RESUMO}

Raele R. Associação da relação cintura-estatura (RCE) com a presença de aterosclerose subclínica mensurada pelo escore de cálcio coronariano $(C A C)$ e pela espessura íntima média da carótida (EIMC) [dissertação]. São Paulo: Faculdade de Medicina, Universidade de São Paulo; 2019.

A Relação Cintura-Estatura (RCE) foi introduzida mais recentemente como uma nova medida para detectar a obesidade central. O objetivo deste estudo foi observar a associação da RCE com a aterosclerose subclínica medida pelo Escore de Cálcio Coronariano (CAC) e pela Espessura Íntima Média da Carótida (EIMC). A análise incluiu 4261 participantes do exame de base (2008-2010) do Estudo Longitudinal Brasileiro de Saúde do Adulto - ELSA-Brasil com informações sobre os quintis da RCE, CAC categorizados como 0 ou $>0$ e $<100$ ou $\geq 100$ unidades de Agatston e EIMC categorizada como $<$ percentil 75 ou $\geq$ percentil 75 . Utilizando o $1^{\circ}$ quintil como referência, observamos uma razão de chances (IC; Intervalo de Confiança 95\%) no $5^{\circ}$ quintil de RCE respectivamente de $1,68(1,26-2,25)$ para $C A C>0$ e $1,36(0,89-2,09)$ para $C A C \geq 100$ após ajuste multivariado para fatores sociodemográficos e de risco cardiovascular. No modelo de regressão linear, a RCE apresentou associação positiva com EIMC nos modelos ajustados para fatores sociodemográficos e de risco cardiovascular com Beta de $0,22(0,17$ a 0,27$)$. A RCE foi associada à aterosclerose subclínica medida pelo CAC e pela EIMC. O presente estudo é uma análise transversal. Embora a RCE tenha sido associada ao aumento do CAC na linha de base, ressalta-se que análises futuras prospectivas no ELSA-Brasil podem avaliar a associação desta medida com a progressão do CAC e também com a progressão de EIMC.

Descritores: Antropometria; Fatores de risco; Aterosclerose; Circunferência da cintura; Gordura abdominal; Doenças da aorta. 


\begin{abstract}
Raele R. Association of waist-to-height ratio (WHtR) with the presence of subclinical atherosclerosis measured by coronary calcium score (CAC) and mean intimal carotid thickness (EIMC). [dissertation]. São Paulo: "Faculdade de Medicina, Universidade de São Paulo"; 2019.

Waist to height ratio (WHtR) was introduced more recently as a new measure for detecting central obesity. The aim of this study is to evaluate the association of WHtR with subclinical atherosclerosis measured by Coronary Artery Calcium (CAC) and carotid intima-media thickness (CIMT). The analysis included 4261 participants of ELSA-Brasil baseline examination with information about quintiles of waist-to-height ratio, and CAC categorized as 0 vs $>0$ and $<100$ vs. $\geq 100$ Agatston units and CIMT categorized as $<75$ th percentile or $\geq 75$ th percentile. Using the $1^{\text {st }}$ quintile as reference, we observed an odds ratio (OR; $95 \%$ Confidence Interval) in the $5^{\text {th }}$ quintile of WHtR respectively of $1.68(1.26-2.25)$ for $\mathrm{CAC}>0$ and $1.36(0.89-2.09)$ for $\mathrm{CAC} \geq 100$ after multivariate adjustment for sociodemographic and, cardiovascular risk factors. In the linear regression model, WHtR was positively associated with CIMT in models adjusted for sociodemographic and cardiovascular risk factors with beta of $0.22(0.17$ to 0.27$)$. WHtR was associated with subclinical atherosclerosis as measured by CAC and CIMT. The present study is a cross-sectional analysis. Although WHtR has been associated with increased baseline CAC, it is noteworthy that future prospective analyzes in ELSA-Brazil may assess the association of this measure with CAC progression and also with CIMT progression.
\end{abstract}

Descriptors: Antropometry; Risk factors; Carotid artery diseases; Waist circumference; Abdominal fat; Aortic diseases. 



\section{INTRODUÇÃO}

\subsection{Importância das Doenças Cardiovasculares}

As doenças cardiovasculares (DCV) são a principal causa de mortalidade no mundo tanto em países de alta renda quanto nos países de média e baixa renda (Global, regional, and national age-sex-specific mortality and life expectancy, 2018; Global, regional, and national age-sex-specific mortality for 282 causes foe death, 2018). Nas últimas décadas as DCV assumiram as primeiras posições como causa de morte e de incapacidade. Embora estratégias de prevenção tenham levado a uma diminuição da mortalidade, ela se estagnou nos últimos anos. Em números absolutos, a mortalidade vem aumentando em função do crescimento populacional (Global, regional, and national agesex-specific mortality and life expectancy, 2018; Global, regional, and national age-sexspecific mortality for 282 causes foe death, 2018).

O número de anos de vida perdidos (Years of Life Lost - YLL) colocou a doença isquêmica coronariana na primeira posição entre as doenças que se associam ao maior número de anos de vida perdidos (primeira posição a partir de 2017) e o acidente vascular cerebral (AVC), na terceira posição desde 2017. Mesmo que o número de YLL tenha diminuído para as duas doenças nos últimos anos, elas permanecem nas primeiras posições e persistem como as principais causas de morte e de anos de vida perdidos por morte ou incapacidade. Cabe destacar que a doença cardiovascular é altamente prevenível, desde que se criem políticas públicas de saúde com esse objetivo, mostrando a importância do estudo de novos fatores de risco (Global, regional, and national age-sexspecific mortality and life expectancy, 2018; Global, regional, and national age-sexspecific mortality for 282 causes foe death, 2018).

\subsection{Doenças cardiovasculares no Brasil}

Os anos 60 no século passado foram caracterizados pela mudança no padrão de causas de morbidade e mortalidade de uma predominância de doenças infecciosas e fatores nutricionais para o predomínio das doenças crônicas, destacando-se as DCV como 
as mais importantes (Brant et al., 2017). Desde 1990 quando a doença isquêmica coronariana era a $4^{\mathrm{a}}$ causa em termos de anos de vida perdidos houve um aumento de $27,5 \%$ até que ela assumisse a $1^{\text {a }}$ posição no Brasil em 2016. As DCV foram responsáveis por 267.635 mortes em 1990 (29,3\% do total) e por 424.058 em 2015 (31,2\%). Durante esse mesmo período, a taxa de mortalidade por DCV ajustada pela idade sofreu uma redução de 429,5 para 256,0 por 100.000 habitantes, mostrando um declínio de 40,4\%. A análise por estado mostra uma variação regional importante, com os estados mais pobres apresentando uma redução menor da mortalidade. Análises prévias realizadas no Brasil mostram que indivíduos da raça negra e com pior status socioeconômico apresentam uma mortalidade mais elevada pelas DCV, sendo o grupo com maior ocorrência de mortes prematuras devidas as DCV (Lotufo et al., 2015). A mortalidade prematura em indivíduos entre 30 e 69 anos impacta de forma significativa a vida dos indivíduos afetados gerando custos para o sistema de saúde e instabilidade econômica nas famílias (Malta et al., 2013). Dados brasileiros também mostram diferenças de acordo com o sexo que seguem o padrão mundial. À medida que o nível de desenvolvimento aumenta, a mortalidade devida a doenças DCV tende a se reduzir primeiro nas mulheres e depois nos homens (Ribeiro et al., 2016; Burden, 2018).

A redução na mortalidade pelas DCV alcançou um platô no Brasil nos últimos anos sugerindo a necessidade de novas estratégias de prevenção. Há um esforço mundial para a redução e controle dos fatores de risco dentro da estratégia para diminuir o impacto das doenças crônicas especialmente o das DCV nas próximas décadas. Em 2012, na Assembleia da Organização Mundial da Saúde (OMS), 194 governos concordaram com o objetivo global de diminuir a carga das doenças crônicas, e principalmente de reduzir a mortalidade precoce abaixo dos 70 anos no caso da DCV até 2025. Uma forma de atingir essa meta é a busca de novos fatores de risco a serem incorporados às estratégias de prevenção nos próximos anos (Malta et al., 2013). 


\subsection{Obesidade Mundial e no Brasil}

\subsubsection{Obesidade Mundial}

Segundo a Organização da Saúde, Obesidade é definida como acúmulo anormal ou excessivo de gordura, que pode prejudicar a saúde. Para adultos, a OMS define obesidade com a presença de Índice de Massa Corporal (IMC) maior ou igual a 30,0. O índice de massa corporal (IMC) é um índice simples, definido com o peso do indivíduo em quilogramas dividido pelo quadrado da sua altura em metros $\left(\mathrm{Kg} / \mathrm{m}^{2}\right)$ (World Health Organization, 2018).

A obesidade é uma doença complexa, com grave dimensão social e psicológica, que afeta praticamente todos os grupos etários e socioeconômicos com grande ônus nos países de alta, baixa e média renda. Desde 1975 a obesidade triplicou seus números em todo mundo. Em 1995, havia cerca de 200 milhões de adultos obesos em todo o mundo. A partir de 2000, este número aumentou para mais de 300 milhões (World Health Organization, 2018). Em 2015, um estudo envolvendo 195 países, demonstrou que o IMC elevado (acima de 25,0$)$ contribuiu para 4,0 milhões de mortes $(7,1 \%)$ por todas as causas e 70\% das mortes relacionadas ao excesso de peso foram devido à doença cardiovascular, sendo que mais de $60 \%$ dessas mortes ocorreram entre pessoas obesas (Afshin et al., 2017).

A epidemia da obesidade mundial não se restringe somente às sociedades industrializadas, nos países de baixa e média renda, estima-se que mais de 115 milhões de pessoas sofrem de problemas relacionados à obesidade (World Health Organization, 2018). 


\subsubsection{Obesidade no Brasil}

No Brasil, resultados de avaliação antropométrica e do estado nutricional da população brasileira realizada a partir da década de 70 através da Pesquisa de Orçamento Familiar (POF) realizada pelo Instituto Brasileiro de Geografia e Estatística (IBGE) também demonstrou um aumento da obesidade de $2,8 \%$ para $12,4 \%$ nos homens e de $8 \%$ para 16,4\% nas mulheres (Instituto Brasileiro de Geografia e Estatística, 2010).

Dados significativos de um dos maiores estudos epidemiológicos da América Latina, o Estudo Longitudinal de Saúde no Adulto (ELSA-Brasil) envolvendo 15 mil indivíduos de seis cidades brasileiras demonstrou a presença de obesidade em $22,9 \%$ da população estudada, com 20,7\% nos homens e 24,8\% nas mulheres (Schmidt et al., 2015).

Nos últimos anos, números crescentes continuam a ser apresentados pelo Vigitel que compõe o sistema de Vigilância de Fatores de Risco para doenças crônicas não transmissíveis (DCNT) do Ministério da Saúde realizada por inquérito telefônico envolvendo 26 estados brasileiros e o Distrito Federal, considerando o Índice de Massa Corporal para classificação de Obesidade segundo critério da OMS (Brasil, 2019). No conjunto das 27 cidades envolvendo uma amostra de mais de 52 mil indivíduos, a frequência de excesso de peso (IMC acima de 25,0) foi de 55,7\%, sendo maior entre homens $(57,8 \%)$ do que entre mulheres $(53,9 \%)$. Desde que este sistema de monitorização foi criado, houve um crescimento considerável do excesso de peso (IMC acima de 25,0) entre a população brasileira, com um aumento de 30,8\% quando comparado com o percentual do ano de 2006, o qual era 42,6\%, apresentando um maior crescimento entre as mulheres $(40 \%)$ do que entre os homens $(21,7 \%)$. Já a frequência de adultos obesos foi de $19,8 \%$, sendo maior entre mulheres $(20,7 \%)$ do que entre homens $(18,7 \%)$. Nesse índice, houve um aumento de 67,8\% nos últimos treze anos, saindo de 11,8\% em 2006 para 19,8\% em 2018 (Brasil, 2019). 
A Organização Mundial de Saúde - OMS aponta a obesidade como um dos maiores problemas de saúde no mundo (World Health Organization, 2019) e no Brasil a situação não é diferente. Frente à projeção da obesidade (IMC $\geq 30,0 \mathrm{~kg} / \mathrm{m}^{2}$ ) em adultos ( $\geq 18$ anos) de $24,8 \%$ em 2022 criou-se a meta nacional de restringir o crescimento da obesidade em adultos em 15\%. Dentre as articulações para prevenção e controle da obesidade, o estímulo à atividade física no cotidiano e ao longo do curso da vida é um dos pontos de destaque; o apoio a iniciativas intersetoriais para o aumento da oferta de alimentos básicos e minimamente processados no contexto da produção, abastecimento e consumo; a estruturação e a implementação de modelos de atenção integral à saúde do portador de sobrepeso e obesidade na rede de saúde, em especial na atenção primária, são algumas das ações de grande importância a serem praticadas (Malta et al., 2013).

\subsection{Obesidade e Risco Cardiovascular}

A relação entre doença cardiovascular e obesidade tem sido amplamente estudada. O aumento de peso levando ao aumento do Índice de Massa Corporal (IMC) tem sido associado ao desenvolvimento de doenças cardiovasculares, incluindo aterosclerose e doença arterial coronariana (DAC), insuficiência cardíaca e fibrilação atrial (Mandviwala, et al., 2016) (Figura 1). 
Figura 1 - Maior risco de doenças cardiovasculares com aumento no Índice de Massa Corporal (IMC)

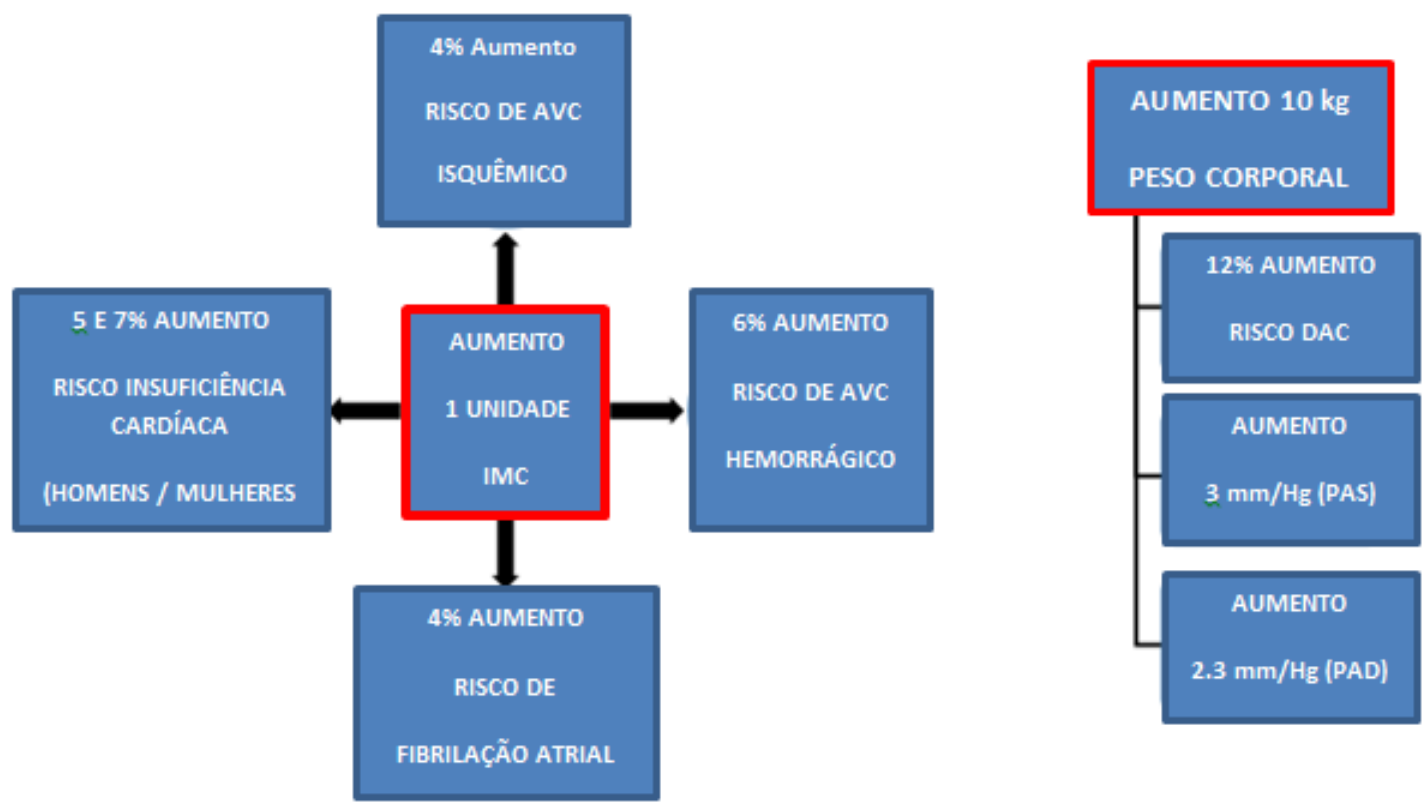

IMC: Índice de Massa Corporal; AVC: Acidente Vascular Cerebral; DAC: Doença Arterial Coronariana; PAS: Pressão Arterial Sistólica; PAD: Pressão Arterial Diastólica

Fonte: Adaptado Obesity and Cardiovascular Disease: a Risk Factor or a Risk Marker?

Curr Atheroscler Rep (2016) 18: 21

Segundo a Organização Mundial da Saúde (OMS), sobrepeso e obesidade são definidos como uma condição onde o excesso ou aumento de gordura abdominal aumentam os riscos à saúde (Schetz et al., 2019). O tecido adiposo corporal é tradicionalmente distribuído em dois compartimentos principais com diferentes características metabólicas: tecido adiposo subcutâneo e tecido adiposo visceral (Shuster et al., 2012).

O comportamento metabólico da gordura visceral difere do tecido adiposo subcutâneo. O primeiro é mais sujeito à lipólise, expressando maior número de receptores de glicocorticoides e é mais sensível às catecolaminas, apresentando menor expressão de substrato-1 do receptor de insulina (IRS-1), o que leva a maior deterioração da 
sensibilidade à insulina, e ao aumento de pressão arterial e do processo aterosclerótico (Barroso et al., 2017). Assim, enquanto ambos os tipos de tecido adiposo são importantes, atenção particular tem sido direcionada para a adiposidade visceral, devido a sua associação com várias patologias (Shuster et al., 2012).

Dependendo do grau, duração e distribuição do excesso de tecido adiposo abdominal, esses riscos à saúde envolvem presença de diabetes tipo 2, hipertensão arterial, doenças cardiovasculares, dislipidemia, doença hepática gordurosa não alcoólica, doença renal crônica, síndrome da apneia obstrutiva do sono e hipoventilação, distúrbios de humor e distúrbios ortopédicos (Schetz et al.,2019).

Um baixo grau de inflamação sistêmica pode, em parte, mediar a relação entre medidas de gordura corporal e doença cardiovascular (Christen et al., 2019). Os estudos envolvendo obesidade e doenças inflamatórias tiveram início na década de 1990, onde a obesidade foi reconhecida como uma doença inflamatória, após um primeiro estudo realizado com ratos, demonstrando maior expressão do gene codificador da adipocitocina pró-inflamatória fator de necrose tumoral-alfa (TNF- $\alpha$ ) no tecido adiposo, além de uma redução da sensibilidade à insulina após exposição a uma dieta de ganho de peso (Hotamisligil et al., 1993).

Indivíduos com excesso de peso apresentam maior secreção de adipocitocinas próinflamatórias e menor das anti-inflamatórias, caracterizando a obesidade como uma inflamação crônica, o que promove grande impacto em diversas funções corporais que estão fortemente correlacionadas a doenças cardiovasculares, resistência insulínica, hipertrigliceridemia e hipercolesterolemia (Sippel et al., 2014). A adiposidade abdominal, particularmente a gordura visceral, tem se mostrado associada à dislipidemia, caracterizada por altos níveis circulantes de lipoproteína total de densidade muito baixa (VLDL), triglicérides, baixos níveis de lipoproteína de alta densidade (HDL)-colesterol e 
partículas menores e mais densas de lipoproteínas de baixa densidade (LDL), apesar dos níveis relativamente normais de colesterol total e LDL-colesterol (Piche et al., 2018).

Estudos epidemiológicos demonstram por sua vez que a obesidade central está altamente associada à hipertensão (Gao et al., 2016; Nurdiantami et al., 2018), à presença de diabetes tipo 2 (Caspard et al., 2018), à doença coronariana (Fuster et al., 2016) e ao aumento da mortalidade cardiovascular (Lee et al., 2018).

\subsection{Medidas Antropométricas na Avaliação da Obesidade}

\subsection{1 Índice de Massa Corporal}

Segundo a Organização Mundial da Saúde a obesidade é definida simplesmente como uma doença de acúmulo anormal ou excessivo de gordura no tecido adiposo, de modo a prejudicar a saúde (World Health Organization, 1998).

O Índice de Massa Corporal (IMC) é um índice simples comumente utilizado para classificar o peso em baixo peso, normal, sobrepeso e obesidade em adultos. Definido como o peso em quilogramas dividido pelo quadrado da altura em metros $\left(\mathrm{Kg} / \mathrm{m}^{2}\right)$ (World Health Organization, 1998). Na população brasileira, tem-se utilizado a tabela proposta pela OMS para classificação de sobrepeso e obesidade. A classificação está apresentada na Figura 2. 
Figura 2 - Classificação Internacional de Obesidade segundo a Organização Mundial da Saúde

\begin{tabular}{cl} 
IMC (KG/M²) & CLASSIFICAÇ̃̃o \\
\hline$<18,5$ & Magro ou baixo peso \\
\hline $18,5-24,9$ & Normal ou eutrófico \\
\hline $25-29,9$ & Sobrepeso ou pré-obeso \\
\hline $30-34,9$ & Obesidade \\
\hline $30-39,9$ & Obesidade \\
\hline 240,0 & Obesidade grave \\
\hline
\end{tabular}

Fonte: Adaptado World Health Organization (WHO).

Obesity: Preventing and managing the global epidemic.

Report of a WHO. Consultation on Obesity. Geneva: WHO; 1998

Apesar do IMC ser simples, prático, sem custo, Garn et al, já apresentava algumas limitações quanto ao uso desta avaliação antropométrica, podendo haver diferenças na composição corporal em função do sexo, idade, etnia, prática de atividade física ou sedentarismo, na presença de perda de estatura em idosos devido a cifose, ou em indivíduos edemaciados o que, segundo os autores, colocariam em risco a utilização do IMC como indicador de gordura corporal (Garn et al., 1986). Estudos mais recentes continuam a manter cuidados na interpretação desta medida antropométrica, a qual não reflete a distribuição da gordura corporal, e indivíduos com o mesmo IMC podem apresentar níveis diferentes de massa gordurosa visceral (Neeland et al., 2018; Piche et al., 2018).

A obesidade e mais recentemente o sobrepeso são problemas crescentes em muitos países, incluindo o Brasil, e várias tentativas têm sido feitas para identificar o 
melhor preditor antropométrico de doenças crônicas em diferentes populações (Oliveira et al., 2010).

Embora a obesidade definida pelo IMC contribua para o risco de DCV, o rastreamento da suscetibilidade a complicações metabólicas relacionadas à obesidade pode se beneficiar de uma avaliação mais precisa da localização do depósito de gordura corporal, sendo ilustrada esta situação através de estudos epidemiológicos como o estudo de caso-controle INTERHEART, demonstrando uma associação, mas modesta, do índice de massa corporal com infarto de miocárdio (Yusuf et al., 2004; Piche et al., 2018).

Medidas mais precisas de adiposidade envolvendo a distribuição de gordura corporal, como relação cintura-quadril e circunferência da cintura foram fortemente associadas a eventos cardiovasculares mesmo após ajuste para outros fatores de risco. As medidas de distribuição regional de gordura corporal, além do IMC, são valiosas para avaliar o risco de doença metabólica associada à obesidade. Um foco na distribuição da gordura corporal, em vez de quantificar o total de gordura corporal, é provável que forneça à comunidade médica melhores ferramentas para estratificar e tratar pacientes com problemas metabólicos associados à obesidade (Piche et al., 2018).

A obesidade visceral está associada a um risco maior de distúrbios metabólicos e ocorrência de doenças crônicas. A quantificação da gordura visceral torna-se necessária e também vantajosa na prática clínica, sobretudo por métodos acurados e precisos em substituição aos métodos por imagem, muitas vezes mais onerosos para a população, como a tomografia computadorizada (Roriz et al., 2016; Eickemberg et al., 2019).

Apesar de a tomografia computadorizada ser considerada o método mais preciso para avaliação da gordura abdominal, poucos estudos populacionais têm sido realizados em função do seu elevado custo operacional. Por isto, os indicadores antropométricos parecem ser uma boa alternativa para testes de diagnóstico de obesidade abdominal 
(Pitanga et al., 2011). Dentre os métodos antropométricos propostos para analisar a distribuição central da gordura corporal, destaca-se a relação cintura-quadril, a circunferência da cintura, o índice de conicidade, o diâmetro sagital e recentemente a relação cintura-estatura.

\subsubsection{Circunferência da Cintura}

Uns dos primeiros estudos envolvendo circunferência da cintura com tecido adiposo visceral foram realizados na década de 90 (Pouliot et al., 1994; Lean et al., 1995). Pouliot et al., em seu estudo com 81 homens e 70 mulheres observou que a circunferência da cintura e o diâmetro abdominal sagital apresentaram melhor correlação com a gordura abdominal visceral (medida pela tomografia computadorizada) do que a relação cinturaquadril (Pouliot et al., 1995). Lean et al., por sua vez, em um estudo com 86 homens e 202 mulheres observou que a simples circunferência da cintura representava risco para doença crônica propondo pontos de corte de 80 e $88 \mathrm{~cm}$ para mulheres e 94 e $102 \mathrm{~cm}$ para homens, caracterizando risco (nível 1) e risco aumentado (nível 2). A partir desses referenciais, muitos estudos foram desenvolvidos e as evidências de associação da obesidade abdominal com maior prevalência de morbidades vêm sendo confirmadas (Lean et al., 1995).

A circunferência da cintura deve ser medida no ponto médio entre a margem inferior da última costela ao topo da crista ilíaca, usando uma fita resistente ao estiramento (Figura 3) segundo recomendações da Organização Mundial da Saúde (OMS) e do Center for Disease Control and Prevention, CDC (World Health Organization., 2011; National Health and Nutrition Examination Survey, 2004). É o método mais comumente utilizado na literatura para avaliar a adiposidade visceral, com valores associados à presença de risco cardiovascular considerado muito elevado de 88 para mulheres e $102 \mathrm{~cm}$ para 
homens, seguindo as recomendações da Organização Mundial de Saúde (World Health Organization, 1998).

Figura 3 - Localização da medida da circunferência da cintura

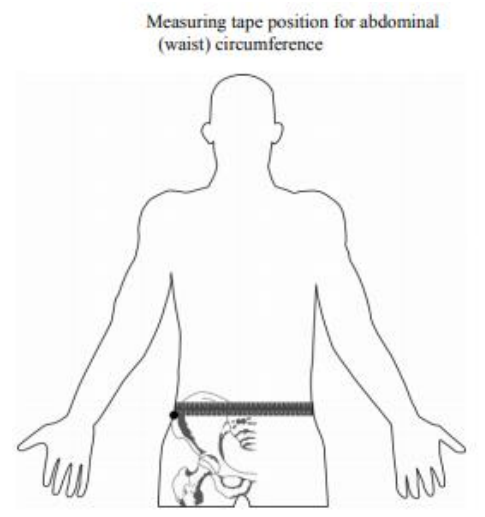

Fonte: Adaptado Anthropometry Procedures Manual. Atlanta. GA:

Center for Disease Control and Prevention; 2004.

\subsubsection{Relação Cintura-Quadril}

Na década de 80, Larsson et al., relacionaram a relação cintura-quadril (RCQ) com o aumento do risco de infarto do miocárdio, acidente vascular encefálico e morte prematura, encontrando forte associação entre essas variáveis em um estudo prospectivo por 13 anos em 794 homens (Larsson et al., 1984).

A RCQ é obtida pela razão da medida da circunferência da cintura $(\mathrm{cm})$ medida no ponto médio entre a margem inferior da última costela ao topo da crista ilíaca, pela medida da circunferência do quadril $(\mathrm{cm})$, tomada em torno da parte mais larga das nádegas (World Health Organization, 2011). Consideram-se valores de risco cardiovascular para relação cintura-quadril acima de 0,90 para homens e acima de 0,85 para mulheres segundo a Organização Mundial de Saúde (World Health Organization, 2011). 
No entanto, a medida da RCQ pode refletir um conceito abstrato, já que indivíduos com maior concentração de gordura na área do quadril ou em ambas as circunferências podem ter um resultado desta relação, baixa ou normal, onde indivíduos magros e obesos podem apresentar o mesmo valor de RCQ, tornando-se uma medida com maior dificuldade em sua interpretação (Rodrigues et al., 2010).

\subsection{4 Índice de Conicidade}

O Índice de Conicidade (ICO), ou Índice C, trata-se da relação entre o peso corporal, a estatura e a circunferência da cintura feita por meio da equação de Valdez,

$$
\text { Indice } \mathrm{C}=\frac{\text { CircunferênciaCintura }(\mathrm{m})}{0,109 \sqrt{\frac{\text { PesoCorporal }(\mathrm{kg})}{\operatorname{Estatura}(\mathrm{m})}}}
$$

no qual o valor 0,109 é a constante que resulta da raiz da razão entre $4 \pi$ (advindo da dedução do perímetro do círculo de um cilindro) e a densidade média do ser humano de $1050 \mathrm{~kg} / \mathrm{m}^{3}$ (Valdez, 1991). Esta medida tem como ponto principal, a imagem de dois cones com uma base comum para as pessoas que apresentam gordura em volta da região central do tronco e na forma de um cilindro para as pessoas que possuem pouca gordura nessa mesma região. A interpretação do resultado da equação é feita da seguinte forma: se o paciente possui, por exemplo, índice $\mathrm{C}$ de 1,40 significa que a circunferência da sua cintura é 1,40 vezes maior do que ela seria se não houvesse gordura abdominal (Pitanga et al., 2005). Em um estudo sobre o desempenho de indicadores antropométricos em

mulheres brasileiras foram avaliados os diferentes pontos de corte do índice de conicidade, da razão cintura-quadril, da circunferência da cintura e da relação cinturaestatura para discriminar o risco coronariano e obteve-se como resultado que o indicador 
que apresentou o melhor poder discriminatório foi o índice de conicidade, seguido pela relação cintura-quadril, razão cintura-estatura e circunferência da cintura (Almeida et al., 2009).

\subsubsection{Diâmetro Abdominal Sagital}

O diâmetro abdominal sagital (DAS) é uma medida menos conhecida, no entanto, também é uma alternativa para estimar a quantidade de gordura visceral. O DAS representa a altura abdominal, compreendendo a distância entre as costas e o abdômen (Williamson et al., 1993). É uma medida obtida utilizando-se um paquímetro abdominal de feixe móvel portátil. A parte superior do braço do calibrador é levada acima de uma marca abdominal entre as cristas ilíacas (L4-L5). O indivíduo é solicitado a inspirar e expirar suavemente, e o braço do paquímetro levado para baixo para tocar a marca abdominal sem compressão (Figura 4).

O DAS tem sido recomendado como indicador de deposição de gordura abdominal visceral e de avaliação do risco cardiovascular (Seidell et al., 2001; Peterson et al., 2007) Um trabalho realizado por Sampaio et al., propôs um ponto de corte para a avaliação do DAS em brasileiros baseados em uma quantidade de gordura abdominal visceral elevada (superior a $100 \mathrm{~cm}^{2}$ ). Os pontos de corte definidos para indivíduos do sexo feminino e masculino foram de 19,3 e 20,5 cm, respectivamente (Sampaio et al., 2007). 
Figura 4 - Medida do Diâmetro Sagital

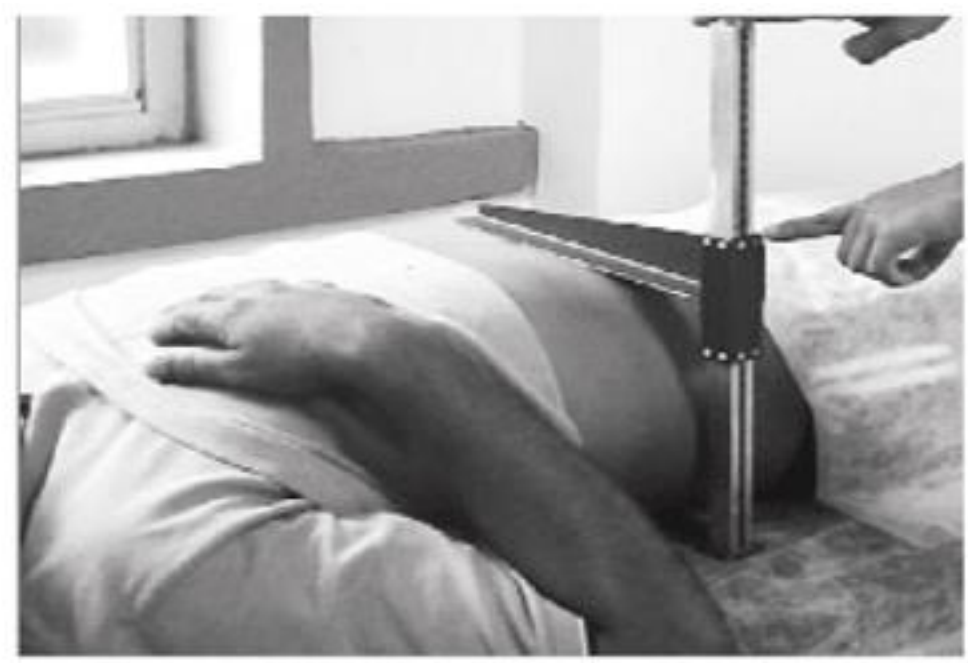

Sagittal abdominal diameter.

Fonte: Adaptado: Validade e confiabilidade do diâmetro abdominal sagital enquanto preditor de gordura abdominal visceral.

Arq Bras Endocrinol Metab. 2007

\subsubsection{Relação Cintura-Estatura}

Recentemente tem recebido atenção especial como marcador de risco à saúde, o uso da Relação Cintura-Estatura (RCE), obtida pela razão da medida da circunferência da cintura $(\mathrm{cm})$ pela medida da altura $(\mathrm{cm})$ para detectar obesidade central e fatores de risco associados (Parikh et al., 2007 Ashwell et al., 2012; Ashwell et al., 2016; Sangrós et al., 2018; Rangel-Baltazar et al., 2019).

A razão da circunferência da cintura pela altura foi originalmente proposta simultaneamente no Japão (Hsieh SD, Yoshinaga H. Waist/height, 1995), na Korea (Lee et al., 1995) e no Reino Unido (Cox et al., 1996; Ashwell M, Cole TJ, Dixon AK et al.,1996).

O estudo de Hsieh et al., avaliou dentre as medidas de obesidade (índice de massa corporal, relação cintura-quadril e relação cintura-estatura) quais apresentaram maior correlação com fatores de risco cardiovascular (hipertensão arterial sistólica e diastólica, 
glicemia de jejum, hemoglobina glicada, colesterol total, HDL-colesterol e triglicérides) em 1077 mulheres japonesas com idade média de 50 anos, demonstrando que os maiores coeficientes de regressão foram consistentemente entre a relação cintura-estatura e a maioria dos fatores de risco por análise de regressão simples $(\mathrm{p}=0,0001)$. Além disso, demonstraram também que a relação cintura-estatura foi a variável independente única para todos ou a maioria dos fatores de risco por análise de regressão múltipla da relação cintura-estatura e IMC ou da relação cintura-estatura e relação cintura-quadril (Hsieh SD, Yoshinaga H. Waist/height, 1995). Resultados semelhantes foram encontrados nos homens em estudo realizado pelos mesmos autores, envolvendo 3131 homens, onde a relação cintura-estatura também foi significativamente associada a todas as variáveis de fatores de risco analisadas comparada às medidas de índice de massa corporal e relação cintura-quadril (Hsieh SD, Yoshinaga H. Abdominal fat, 1995).

Da mesma forma Lee et al., avaliaram diferentes índices de distribuição de gordura corporal (circunferência da cintura e relação cintura-estatura) para rastrear grupos de obesidade de alto risco para doença arterial coronariana em 938 homens, demonstrando que a relação cintura-estatura se correlaciona melhor com fatores de risco como triglicerídeos séricos (TG), pressão arterial diastólica (PAD), e com maior sensibilidade e especificidade para rastreamento de indivíduos com hipertensão arterial (Lee et al., 1995).

Um estudo prospectivo britânico em 1996, através da análise de regressão logística com ajuste para idade e tabagismo em 2184 homens e 2730 mulheres (30 a 79 anos), demonstrou que a relação cintura-estatura foi um preditor significativo $(\mathrm{p}<0,01)$ dos óbitos por todas as causas e por doença cardiovascular em homens e mulheres (Cox et al., 1996). Estudos realizados por Ashwell et al., no mesmo período, também sinalizaram a relevância desta medida como preditora de gordura abdominal e de risco 
cardiovascular. Em um estudo transversal com 31 mulheres e 16 homens saudáveis com idade entre 18 a 73 anos, os pesquisadores demonstraram que a relação cintura-estatura apresentou uma maior correlação com gordura abdominal (medida pela tomografia computadorizada) $(r=0,83)$, do que a circunferência da cintura $(r=0,75)$, índice de massa corporal $(r=0,69)$, e relação cintura-quadril $(r=0,54)(\mathrm{p}<0,001)$ (Ashwell M, Cole TJ, Dixon AK, 1996). Outro estudo, realizado no mesmo período por Ashwell et al., com 1481 mulheres e 1411 homens (30 a 74 anos) demonstrou que o maior coeficiente de correlação com risco de doença arterial coronariana foi obtido com a relação cinturaestatura ( $r=0,38$ para homens e $r=0,31$ para mulheres) comparado a outras medidas antropométricas do estudo (circunferência da cintura, relação cintura-quadril e índice de massa corporal) (Ashwell M, Lejeune S, McPherson K, 1996).

Resultados de uma metanálise com 25 estudos mostraram que a relação cinturaestatura se apresentou como um discriminador mais acurado para hipertensão, diabetes e dislipidemia dentre os índices de sobrepeso e obesidade analisados (índice de massa corporal, circunferência da cintura, relação cintura-quadril e relação cintura-estatura) (Lee et al., 2008). Em 2012, outra revisão e metanálise envolvendo 31 artigos demonstrou uma superioridade da medida da relação cintura-estatura sobre a circunferência da cintura e o índice de massa corporal na detecção de fatores de riscos cardiometabólicos, tanto em homens quanto em mulheres (Ashwell et al., 2012).

Um estudo transversal recente realizado na Espanha por Segura-Fragoso et al., por sua vez, comparou a relação entre índice de massa corporal, circunferência da cintura, relação cintura-estatura e índice de conicidade com o risco cardiovascular estimado pelo Escore de Framingham em 1309 indivíduos acima de 18 anos, demonstrando que a circunferência da cintura e a relação cintura-estatura apresentam melhor discriminação 
do risco cardiovascular comparado ao índice de massa corporal (Segura-Fragoso et al., 2019).

Browning et al., demonstrou em uma revisão envolvendo 16 estudos de 14 países com indivíduos Caucasianos, Asiáticos e da América Central, pontos de corte identificados por meio da Curva ROC "receiver operating characteristic" para a relação cintura-estatura e os fatores de risco cardiometabólicos, de 0,5 tanto para homens quanto para mulheres (Browning et al., 2010), valor este também defendido por Ashwell et al., como um indicador de aumento de risco à saúde (Ashwell et al., 2014).

No Brasil temos poucos estudos utilizando a curva ROC para observar o melhor ponto de corte da relação cintura-estatura para predizer riscos cardiometabólicos (Haun et al., 2009; Rodrigues et al., 2010; Castanheira et al., 2018).

Haun et al., em um estudo com 968 pessoas (391 homens e 577 mulheres) com idade média de 45 anos, observaram o melhor ponto de corte através da curva ROC, da relação cintura-estatura, como discriminador de risco coronariano em adultos, sugerindo valores de 0,52 para homens e 0,53 para mulheres (Haun et al., 2009). Rodrigues et al., em um estudo com 1.655 indivíduos (759 homens e 896 mulheres), avaliaram através da curva ROC que em relação à capacidade de identificar a síndrome metabólica, houve uma superioridade tanto nos homens quanto nas mulheres da relação cintura-estatura $(0,774$ e 0,813; respectivamente) sobre as outras medidas analisadas (índice de massa corporal, circunferência da cintura e relação cintura-quadril), com valores de 0,759; 0,775 e 0,730 nos homens e de 0,$813 ; 0,835 ; 0,779$ nas mulheres, considerando pontos de corte de 0,53 e 0,54 para síndrome metabólica, para homens e mulheres, respectivamente (Rodrigues et al., 2010). 
Recentemente, um estudo transversal de Castanheira et al., demonstraram em 5026 mulheres e 4238 homens com idades entre 35 e 54 anos que participaram do Estudo Longitudinal Brasileiro de Saúde do Adulto (ELSA-Brasil) na linha de base, pontos de corte para risco cardiometabólico (hipertensão, diabetes, hipertrigliceridemia, e síndrome metabólica) da RCE de 0,55 para mulheres e de 0,54 para homens (Castanheira et al., 2018).

Um ponto importante a observar é o local correto da realização da medida da circunferência da cintura (medida que faz parte da relação cintura-estatura), a qual muitas vezes é confundida com circunferência de abdômen (Oliveira et al., 2016).

Estudo conduzido por Wang et al., com homens e mulheres demonstrou diferenças significativas nos pontos de medida da circunferência da cintura frente a presença de gordura abdominal (Wang et al., 2003).

Em um recente estudo transversal com 119 indivíduos com sobrepeso, Pinho et al., avaliaram 6 locais diferentes de medida de CC (menor circunferência da cintura, medida abaixo da costela, ponto médio entre a costela e a crista ilíaca, $2 \mathrm{~cm}$ acima da cicatriz umbilical, imediatamente acima da crista ilíaca, e no nível da cicatriz umbilical) para estimar o grau de variabilidade desta medida anatômica com padrões cardiometabólicos (glicemia em jejum, hemoglobina glicada, colesterol total e frações, triglicérides, razão triglicérides/HDL-colesterol, proteína $\mathrm{C}$ reativa e ácido úrico), apresentando como resultado uma maior variabilidade entre os locais de medição da CC nas mulheres, sendo nos homens a medida da menor circunferência da cintura o maior preditor de alterações na gordura visceral (Pinho et al., 2018).

Assim, torna-se muito importante a adoção de protocolos para obter a medição e, portanto, permitindo comparações válidas entre os estudos. 


\subsection{Aterosclerose Subclínica}

\subsubsection{Escore de Cálcio Coronariano (CAC)}

O índice de calcificação de artéria coronária, coronary artery calcification (CAC) é um escore obtido a partir da tomografia computadorizada. É um escore que evidencia o conceito de idade vascular, além da idade cronológica sendo obtido por meio da técnica de Agatston (Agatston et al., 1990).

A caracterização de calcificações nas artérias coronárias por meio da tomografia computadorizada tem equivalência com a carga aterosclerótica coronariana global e com o risco de eventos cardiovasculares. Esta calcificação nas artérias coronárias é um indicador do surgimento e dimensão da doença aterosclerótica do indivíduo com forte ligação com a incidência de eventos cardiovasculares futuros (Buddoff et al., 2006). O volume das placas calcificadas em fase cicatricial avançada nas artérias coronárias está associado ao processo inflamatório no local, sendo um instrumento útil na análise do risco cardiovascular apresentando um papel relevante na estratificação de risco cardiovascular, com significativa associação com a ocorrência de eventos cardiovasculares maiores no acompanhamento de médio e longo prazo (Neves et al., 2017). Este processo de calcificação de placas ateroscleróticas ocorre devido à inflamação, morte celular e deposição de colesterol. A fração LDL-colesterol, sofrendo oxidação, convoca células T e macrófagos para o local lesionado, os quais impulsionam proteínas morfogenéticas do osso que causam à indução osteoblástica, resultando na calcificação (Hunt et al., 2002).

A calcificação da artéria coronária é um forte marcador da aterosclerose subclínica, particularmente em indivíduos assintomáticos, sendo um importante preditor de eventos cardiovasculares (Detrano et al., 2008; Erbel et al., 2010, Yu et al., 2013). 
Quanto maior a pontuação do CAC, maior o risco de eventos cardiovasculares futuros. (Raggi et al., 2000; Buddoff et al., 2002).

Detrano et al., analisaram o escore de cálcio e os desfechos cardiovasculares em uma amostra de 6722 indivíduos de diferentes grupos populacionais $(38,6 \%$ brancos, 27,6\% negros, 21,9\% hispânicos e 11,9\% chineses) acompanhados por 3,8 anos. Em comparação com participantes com escore de cálcio igual a zero, o risco ajustado de um evento coronariano foi 7,73 maior entre participantes com CAC entre 101 e 300 e 9,67 entre os participantes com CAC acima de 300 ( $\mathrm{p}<0,001$ para ambas as comparações). As análises mostraram ainda que, para cada grupo étnico, o risco para qualquer dos desfechos aumentou de $15 \%$ para $35 \%$ ao se duplicar o escore de CAC, e para os eventos maiores (infarto agudo do miocárdio e morte súbita) o risco aumentou de $18 \%$ para $39 \%$ (p $<0,02)$, levando a conclusão de que a medida do CAC melhora o valor preditivo de doença arterial coronariana para os grupos étnicos do estudo (Detrano et al., 2008).

Quando comparado com outro marcador de aterosclerose subclínica (EIMC), o CAC tem se mostrado melhor preditor para a incidência de doença cardíaca coronariana e doença cardiovascular total. No entanto a EIMC foi um preditor modestamente melhor que o CAC para acidente vascular cerebral (Folsom et al., 2008).

Há poucos estudos na literatura avaliando índices de obesidade com aterosclerose subclínica medida pelo CAC (Cassidy et al, 2005; Kramer et al., 2009; OH et al., 2016). Cassidy et al., em um estudo prospectivo por 8.9 anos, com 443 indivíduos assintomáticos (243 homens e 200 mulheres) com idade acima de 30 anos, observaram associação significativa da progressão de CAC com circunferência da cintura $(\mathrm{p}=0,024)$, relação cintura-quadril ( $\mathrm{p}<0,001)$, índice de massa corporal $(\mathrm{p}=0,036)$ e excesso de peso em comparação com baixo peso ou com peso normal $(p=0,008)$. (Cassidy et al., 2005). Em outro estudo, Kramer et al., demonstraram associação de diversas medidas 
antropométricas de obesidade (circunferência da cintura, relação cintura-quadril e relação cintura-estatura), de gordura visceral e subcutânea (medidas pela tomografia computadorizada), com a progressão de CAC em 156 homens e 182 mulheres com idade média de 67 anos após 4,5 anos de acompanhamento (Kramer et al., 2009).

\subsubsection{Espessura Íntima Média da Carótida (EIMC)}

A EIMC também é um marcador de aterosclerose subclínica (Grobbee et al., 1994) sendo preditor de futuros eventos cardiovasculares como infarto do miocárdio e acidente vascular cerebral (Dahlen et al., 2009).

A formação das placas ateroscleróticas é lenta e gradual, iniciando-se com a passagem de lipoproteínas de baixa densidade através do endotélio para o espaço subendotelial. A disfunção endotelial, caracterizada pela maior permeabilidade do endotélio às lipoproteínas, iniciaria o processo de formação da placa, seguida pela oxidação de LDL-colesterol desencadeando reação inflamatória local. A proliferação de fibroblastos e a migração de células musculares lisas da camada média para o espaço subendotelial podem ser medidas pela espessura íntima média das artérias carótidas (EIMC) (Mill et al., 2013).

A medida da espessura médio-intima das carótidas (EIMC) é estimada pela ultrassonografia de alta resolução das artérias carótidas. O espessamento da parede da carótida e a placa da carótida podem refletir a presença de alteração vascular aterosclerótica precoce sendo um preditor independente de eventos cardiovasculares futuros. A medida EIMC é relativamente simples, não invasiva e pode ser útil para avaliação de rastreamento de indivíduos com presença de obesidade abdominal para estratificação de risco cardiovascular (Tongdee et al., 2016). 
Estudos prospectivos prévios têm mostrado associação entre diferentes índices de obesidade e medida de EIMC (Folsom et al., 1994; Lakka et al., 2001; De Michele et al., 2002). Folsom et al., em um estudo com 6474 homens e 7956 mulheres por 2 anos, demonstraram que adiposidade abdominal (medida pela circunferência da cintura), sedentarismo e alteração da glicemia estão associadas positivamente com a progressão de EIMC. De Michele et al., demonstraram que nas análises multivariadas, IMC e relação cintura-quadril foram preditores significativos da EIMC da carótida, independente de outros riscos cardiovasculares (idade, pressão arterial, alterações lipídicas, insulina em jejum), corroborando com outro estudo realizado por Lakka et al., em 774 homens de meia-idade por 4 anos de segmento, onde mostraram que a obesidade central medida pela circunferência cintura e relação cintura-quadril estava associada a um aumento acelerado da aterosclerose medida pela EIMC, independente de outros fatores de risco cardiovascular (De Michele et al., 2002; Lakka et al., 2001).

No Brasil, temos poucos estudos comparando diferentes indicadores de adiposidade com a EIMC (Santos et al.,2015; Baena et al., 2016; Eickemberg et al., 2019). Em ambos os estudos, Santos et al., e Baena et al., consideraram a circunferência do pescoço como um indicador associado a EIMC, sugerindo que o efeito local produzido pela gordura do pescoço atue nas artérias carótidas (Santos et al., 2015; Baena et al., 2016).

Eickemberg et al., em um recente estudo, avaliaram em 8449 indivíduos adultos (3737 homens e 4712 mulheres) a associação entre adiposidade abdominal (circunferência da cintura, relação cintura-quadril, índice de conicidade, produto de acumulação lipídica e índice de adiposidade visceral) e EIMC, demonstrando através de regressão logística multivariada ajustada por fatores sociodemográficos e 
cardiovasculares, associação entre o diagnóstico destas medidas de adiposidade central com EIMC em ambos os sexos (Eickemberg et al., 2019). 


\section{OBJETIVOS}

\subsection{Objetivo Principal}

O objetivo deste estudo transversal é avaliar a associação da Relação CinturaEstatura (RCE) com a aterosclerose subclínica medida por dois marcadores de aterosclerose subclínica - CAC e EIMC - mensurados na linha de base do Estudo Longitudinal de Saúde do Adulto (ELSA-Brasil).

\subsection{Objetivos Secundários}

Determinar as características sócio demográficas e clínicas da amostra de acordo com a relação cintura-estatura (RCE);

Determinar as características sócio demográficas e clínicas da amostra de acordo com a relação cintura-estatura $(\mathrm{RCE})$ por sexo;

Avaliar a associação da relação cintura-estatura (RCE) com o CAC de acordo com o sexo;

Avaliar a associação da relação cintura-estatura (RCE) com a EIMC de acordo com o sexo. 


\section{HIPÓTESE}

Há uma associação positiva da relação cintura-estatura (RCE) com a aterosclerose subclínica mensurada pelo CAC e pela EIMC. Valores mais elevados da relação cinturaestatura (RCE) se associam a presença de mais aterosclerose subclínica medida pelo CAC e pela EIMC. 


\section{MÉTODOS}

\subsection{Caracterização do Estudo}

O Estudo Longitudinal da Saúde do Adulto (ELSA-Brasil) é um estudo multicêntrico, de coorte, que inclui 15.105 indivíduos funcionários públicos (6887 homens e 8218 mulheres), com idades entre 35 e 74 anos residentes em seis cidades diferentes no Brasil (Belo Horizonte, Porto Alegre, Rio de Janeiro, Salvador, São Paulo e Vitória), com o objetivo de determinar a incidência de doenças cardiovasculares, do diabetes e os fatores de risco associados incluindo fatores biológicos, comportamentais, ambientais, ocupacionais e sociais. (Aquino et al, 2012; Benseñor et al, 2013; Schimidt et al, 2015).

A estimativa do tamanho da amostra foi baseada na incidência de doenças cardiovasculares e diabetes na população brasileira de forma conservadora em um acumulado de 3 anos em 1,4\% considerando-se um valor de alfa de 5\%, poder estatístico de $80 \%$, prevalência de exposição de $20 \%$ e um risco relativo de 2,0. Baseado nesses índices chegou-se a um tamanho da amostra de aproximadamente 6,400 indivíduos. A fim de possibilitar análises específicas por sexo e permitir possíveis perdas no acompanhamento, foi definido o tamanho da amostra desejada como aproximadamente 15.000 indivíduos.

Os critérios de inelegibilidade para participar do estudo foram contratação recente, gravidez (menos de 4 meses entre o parto e a primeira entrevista), intenção de deixar de trabalhar na instituição em futuro próximo, comprometimento cognitivo ou de comunicação grave, e, se aposentado, residir fora da área metropolitana correspondente 
ao Centro de Investigação. Exceto por esses critérios todos os funcionários na faixa etária de 35 a 74 anos foram considerados como elegíveis a participar do estudo.

Como o escore de cálcio (CAC) foi medido somente no Centro de Investigação de São Paulo como parte da linha de base do estudo, amostra abrangeu 4261 participantes de São Paulo com mensuração do CAC e da EIMC.

\subsection{Aspectos Éticos da Pesquisa}

O estudo ELSA-Brasil foi aprovado pelos Comitês de Ética em Pesquisa dos seis centros. Ele seguiu as diretrizes estabelecidas pela Declaração de Helsinque. Todos os participantes leram e assinaram o Termo de Consentimento Livre e Esclarecido (TCLE). O número de aprovação no Comitê de Ética em Pesquisa do Hospital Universitário foi $1665 / 17$

\subsection{Coleta de dados}

O Estudo Longitudinal de Saúde do Adulto (ELSA-Brasil) incluiu em seu protocolo exames e entrevistas que exigiram a visita do voluntário ao centro de pesquisa clínica. O volume de informações buscadas na linha de base por meio de entrevistas e exames levou à divisão dessa etapa em duas fases. Na Fase 1 (duração média de uma hora e meia), que ocorria logo após o recrutamento, um entrevistador informava sobre o estudo visando ao consentimento livre e esclarecido. Em seguida era feita uma entrevista e eram dadas instruções para a realização da Fase 2, que durava de cinco a seis horas (Bensenor et al., 2013). 
Cada participante foi entrevistado no local de trabalho e visitou o Centro de Pesquisa no dia da realização dos exames clínicos, seguindo protocolo padronizado igual para todos os centros.

Todas as entrevistas e exames foram realizados sob supervisão e estrito controle de qualidade (Aquino et al, 2012; Bensenor et al 2013; Schimidt et al, 2015).

\subsection{Medidas antropométricas}

As medidas antropométricas incluídas no estudo foram peso, altura e circunferência da cintura, obtidas por meio de critérios técnicos (Lohman, 1988). O peso corporal foi medido com o sujeito descalço, em jejum, vestindo um uniforme padrão. Foi utilizada balança eletrônica (Toledo®, modelo 2096PP), com capacidade de 200 kg, com precisão de 50g. A estatura foi aferida com um estadiômetro de parede (Seca®, Hamburgo, BRD) com precisão de $1 \mathrm{~mm}$, fixado na parede lisa e sem rodapé, com o indivíduo em decúbito dorsal, descalço, com apoio da cabeça, das nádegas e calcanhares na parede, com o olhar no plano horizontal.

A medida da estatura foi verificada no período inspiratório do ciclo respiratório. A circunferência da cintura (CC) foi medida com o participante em jejum e com a bexiga vazia, permanecendo em pé, respirando normalmente com os pés juntos, com uma fita métrica inextensível no ponto médio entre a crista ilíaca e a borda inferior do arco costal (Aquino et al., 2012). O índice de massa corporal (IMC) foi calculado como peso (kg) dividido pela altura ao quadrado $\left(\mathrm{m}^{2}\right)$ (Lohman, 1988). A relação cintura-estatura foi calculada dividindo-se a circunferência da cintura $(\mathrm{cm})$ pela altura $(\mathrm{cm})($ Ashwell et al., 2012). 


\subsection{Medição de Aterosclerose Subclínica}

\subsubsection{Escore de Cálcio Coronariano (CAC)}

O exame do Escore de Cálcio Coronariano (CAC) foi realizado em tomógrafo de 64 cortes (Brilliance 64; Philips Healthcare, Best, Holanda). Após as imagens iniciais, o participante foi submetido a exame de escore de cálcio sincronizado ao eletrocardiograma por três ciclos cardíacos. Foi utilizado tubo com potencial de $120 \mathrm{kV}$. As imagens foram reconstruídas em cortes de espessura de 2,5 mm. O CAC foi expresso como unidades de Agatston e o percentil foi avaliado de forma cega por um cardiologista experiente usando um software semi-automático (Calcium Scoring, Philips Workstation). O escore de cálcio da artéria coronária foi categorizado em 0 ou $>0$ e $<100$ ou $\geq 100$ pontos de Agatston (Agatston et al., 1990; Perreira, et al., 2016; Bensenor et al., 2016).

\subsubsection{Espessura de íntima-média de carótida (EIMC)}

A espessura de íntima-média das carótidas (EIMC) foi medida na parede da artéria mais distante do examinador em um segmento carotídeo pré-definido de $1 \mathrm{~cm}$ localizado a $1 \mathrm{~cm}$ da bifurcação carotídea, durante 3 ciclos cardíacos. Todas as imagens foram lidas no Centro de Leitura de Ultrassonografia em São Paulo onde passaram por avaliação de controle de qualidade. Foi utilizado o software MIA (Coralville, IA) para padronizar a leitura e interpretação dos exames de EIMC. Neste trabalho, definiu-se o valor médio da média aritmética das medidas da EIMC das artérias carótida direita e esquerda. Valores de EIMC alterados foram definidos como maior ou igual do percentil 75 (Mill et al., 2013; Santos et al., 2014; Rosval et al., 2015). 


\subsection{Outras variáveis de interesse}

Foram coletadas características sociodemográficas como sexo; idade (anos); nível de escolaridade (ensino fundamental, ensino médio ou superior incompleto e ensino superior completo ou pós-graduação); renda familiar média mensal $(\leq \mathrm{R} \$ 2490,00, \mathrm{R} \$$ 2491,00 a $\mathrm{R} \$ 6638,00$ e $\geq \mathrm{R} \$ 6639,00$ ); além de etnia/cor da pele autodeclarada (preto, pardo, branco, asiático e indígena). Tabagismo e etilismo foram categorizados como nunca, passado ou atual (Aquino et al., 2012).

A atividade física de lazer foi classificada de acordo com o critério da Organização Mundial de Saúde, utilizando o Questionário Internacional de Atividade Física (IPAQ), no qual os fisicamente ativos eram aqueles com pelo menos 150 minutos de intensidade moderada ou 75 minutos de atividade física de alta intensidade ou equivalente combinado de ambas as semanas. Qualquer atividade semanal abaixo do nível já descrito foi classificada como parcialmente ativa e o restante como ausência de atividade física (Treff et al., 2017).

A pressão arterial (PA) foi medida utilizando-se um dispositivo oscilométrico validado (Omron HEM 705CPINT). Três medidas de pressão arterial foram tomadas em intervalos de um minuto e a média das duas últimas medições foi considerada como o valor para definir a pressão casual. A hipertensão foi definida como o uso de medicamentos para tratar a hipertensão ou pressão arterial sistólica $\geq 140 \mathrm{mmHg}$ ou pressão arterial diastólica $\geq 90 \mathrm{mmHg}$. Diabetes foi definido como história pregressa de diabetes, uso de medicamentos para tratamento de diabetes, glicemia de jejum $\geq 125 \mathrm{mg}$ / dL, glicemia de 2 horas após sobrecarga de 75 g de glicose $\geq 200 \mathrm{mg} / \mathrm{dL}$ ou HbA1C $\geq$ 
6,5\%. Dislipidemia foi definida como LDL-colesterol >130 mg / dl ou uso de medicação hipolipemiante (Schmidt et al., 2014).

\subsection{Exames Laboratoriais}

Os exames laboratoriais foram realizados em amostra de soro coletadas dos participantes após 12 horas em jejum. Uma segunda coleta foi realizada após 120 minutos após ingestão de sobrecarga de glicose ou carga alimentar (diabéticos) como parte do teste de tolerância oral a glicose. A glicemia foi determinada pelo método enzimático, utilizando o equipamento ADVIA 1200 (Siemens ${ }^{\circledR}$ ). O colesterol total foi dosado pelo método da colesterol oxidase (enzimático colorimétrico) utilizando o equipamento ADVIA 1200 (Siemens ${ }^{\circledR}$ ); o colesterol de lipoproteínas de baixa densidade (LDLcolesterol) foi calculado pela Equação de Friedewald na presença de triglicérides $<400$ mg/dL ou pelo método enzimático colorimétrico homogêneo sem precipitação, na presença de triglicerídeos superiores a $400 \mathrm{mg} / \mathrm{dL}$ utilizando o equipamento ADVIA 1200 $\left(\right.$ Siemens $\left.{ }^{\circledR}\right)$. O HDL-colesterol foi dosado pelo método calorimétrico homogêneo sem precipitação utilizando também o equipamento ADVIA 1200 (Siemens ${ }^{\circledR}$ ) (Fedeli et al, 2013).

\subsection{Critérios de Exclusão}

Foram excluídos da análise total os seguintes participantes: participantes com história prévia de doença cardiovascular (doença arterial coronariana, infarto agudo do 
miocárdio, acidente vascular cerebral e revascularização) e participantes que não tinham as duas medidas de aterosclerose subclínica: CAC e EIMC.

\subsection{Análise Estatística}

As variáveis categóricas foram apresentadas como frequências absolutas e relativas e comparadas usando teste do qui-quadrado.

As variáveis contínuas foram apresentadas como média e desvio padrão e comparadas usando-se ANOVA unidirecional com teste post hoc de Bonferroni; ou mediana [intervalo interquartil] comparadas usando-se o teste de Mann- Whitney ou Kruskal-Wallis conforme necessário.

A relação cintura-estatura foi dividida em quintis. O escore de cálcio coronariano foi categorizado como 0 ou $>0$ e $<100$; $\geq 100$; e a EIMC foi categorizada como < percentil 75 ou $\geq$ percentil 75 ou utilizada como variável contínua.

Os modelos de regressão logística foram construídos considerando-se os quintis da razão cintura-estatura como variáveis independentes e o escore de CAC e a EIMC como dependentes, usando-se o primeiro quintil como referência. A Razão de Chances (RC) e Intervalos de Confiança de 95\% (IC 95\%) foi apresentada na forma bruta, ajustadas para fatores de risco sociodemográficos, como idade, sexo, raça e escolaridade (Modelo 1); com posterior ajuste para os fatores de risco cardiovasculares como hipertensão, diabetes, dislipidemia, tabagismo, ingestão de álcool e atividade física (Modelo 2).

Os modelos de regressão linear foram apresentados na forma bruta sem ajuste e com os mesmos ajustes apresentados nos modelos logísticos. 
Todas as análises foram realizadas com o Statistical Package for Social Sciences, versão 22 (SPSS Inc., Chicago, Illinois, EUA). O valor de $\mathrm{p}<0,05$ foi considerado como estatisticamente significativo. 


\section{RESULTADOS}

Nesta análise foram incluídos os participantes do Centro de Investigação São Paulo que fizeram o CAC na linha de base do estudo. Dos 5061 participantes de São Paulo, 4549 fizeram CAC como parte dos exames realizados na linha de base. Desses foram excluídos todos os indivíduos com história prévia de doença cardiovascular $(n=150)$ e que não tinham informação sobre a Espessura de Íntima-Média de Carótida (EIMC) $(n=138)$, totalizando, portanto, 4261 participantes no presente no estudo (Figura $5)$. 
Figura 5 - Fluxograma do Critério de Seleção da Amostra

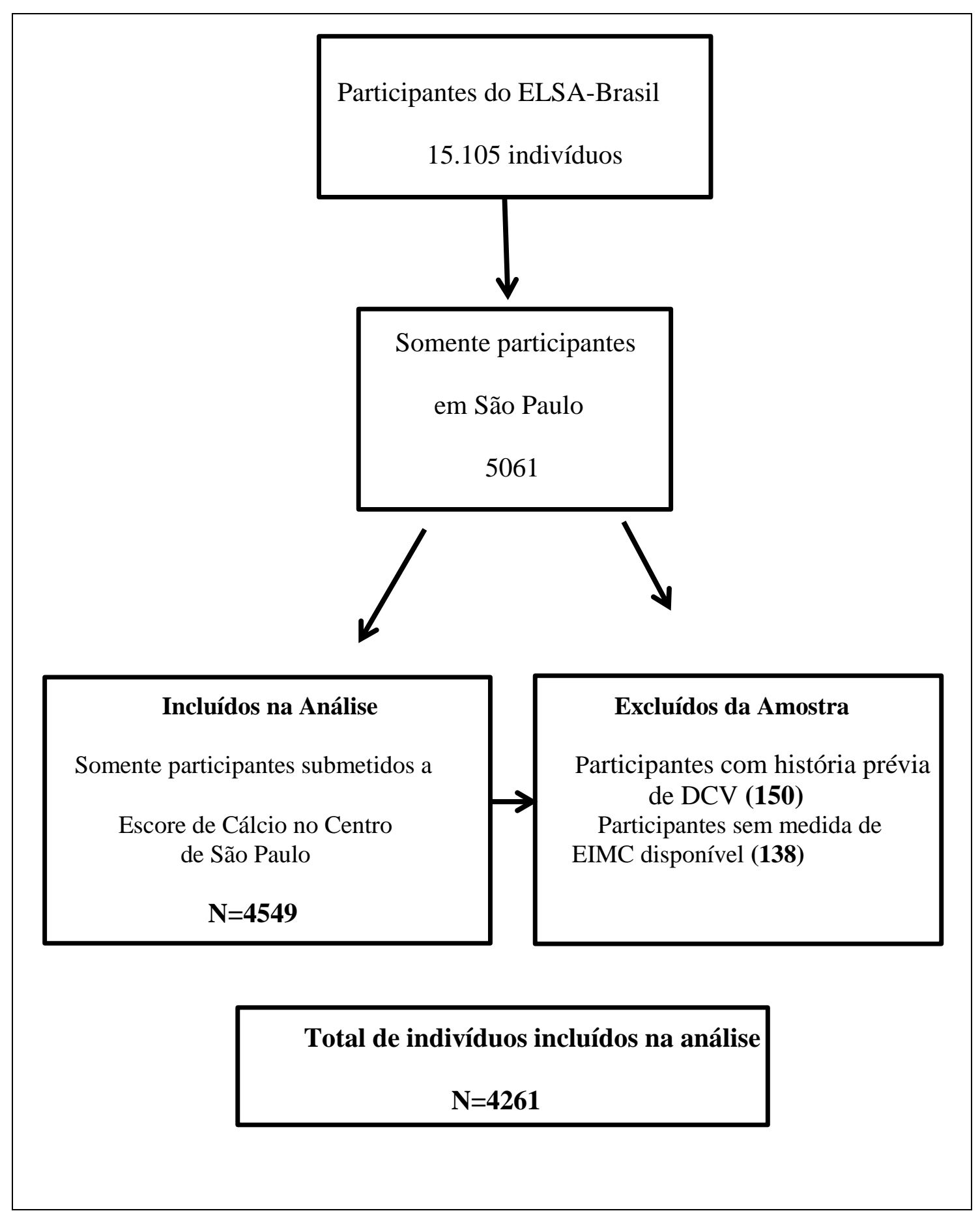


Tabela 1 - Características sociodemográficas da amostra.

\begin{tabular}{|c|c|c|c|c|c|c|}
\hline \multicolumn{7}{|c|}{ Quintis da Relação Cintura-Estatura } \\
\hline \multirow{3}{*}{ Quintis } & $1^{\mathrm{st}}$ & $2^{\text {st }}$ & $3^{\text {st }}$ & $4^{\mathrm{st}}$ & $5^{\mathrm{st}}$ & $\mathrm{P}$ valor \\
\hline & $\leq 0.48$ & $0.48-0.52$ & $0.53-0.56$ & $0.57-0.60$ & $>0.61$ & $<0.0001$ \\
\hline & 852 & 852 & 853 & 852 & 852 & \\
\hline Idade (anos) & $47.8(8.3)$ & $49.7(8.2)$ & $50.9(8.3)$ & $51.8(8.7)$ & $53.1(9.0)$ & $<0.0001$ \\
\hline Raça $(\%)$ & & & & & & $<0.0001$ \\
\hline Brancos & $518(61.3)$ & $505(60.1)$ & $490(58.3)$ & $474(56.7)$ & $484(57.3)$ & \\
\hline Pardos & $166(19.6)$ & $179(21.3)$ & $177(21.1)$ & $204(24.4)$ & $197(23.3)$ & \\
\hline Pretos & $106(12.5)$ & 99 (11.8) & $122(14.5)$ & $123(14.7)$ & $135(16.0)$ & \\
\hline Asiáticos & $52(6.2)$ & $50(6.0)$ & $40(4.8)$ & $23(2.8)$ & $18(2.1)$ & \\
\hline Indígenas & $3(0.4)$ & $7(0.8)$ & $11(1.3$ & $12(1.4)$ & $11(1.3)$ & \\
\hline Nível Educacional (\%) & & & & & & $<0.0001$ \\
\hline Ensino Fundamental & $76(8.9)$ & $95(11.2)$ & $114(13.4)$ & $160(18.8)$ & $178(20.9)$ & \\
\hline $\begin{array}{l}\text { Ensino Médio e } \\
\text { Superior Incompleto }\end{array}$ & $333(39.1)$ & $342(40.1)$ & $362(42.4)$ & $356(41.8)$ & $374(43.9)$ & \\
\hline $\begin{array}{l}\text { Ensino Superior Completo ou Pós- } \\
\text { graduação }\end{array}$ & $443(52.0)$ & $415(48.7)$ & $377(44.2)$ & $336(39.4)$ & $300(35.2)$ & \\
\hline Renda Mensal Familiar (\%) & & & & & & $<0.0001$ \\
\hline$\leq \mathrm{R} \$ 2490,00$ & $264(31.2)$ & $227(26.7)$ & $255(30.1)$ & $305(36.0)$ & $296(34.9)$ & \\
\hline $\mathrm{R} \$ 2491,00$ a $\mathrm{R} \$ 6638,00$ & $337(39.8)$ & $332(39.0)$ & $339(40.0)$ & $294(34.7)$ & $327(38.5)$ & \\
\hline$\geq \mathrm{R} \$ 6639,00$ & $246(29.0)$ & $292(34.3)$ & 253 (29.9) & $249(29.4)$ & $226(26.6)$ & \\
\hline
\end{tabular}


Tabela 2 - Características clínicas da amostra.

\begin{tabular}{|c|c|c|c|c|c|c|}
\hline \multirow[b]{3}{*}{ Quintis } & \multicolumn{5}{|c|}{ Quintis da Relação Cintura-Estatura } & \multirow[b]{2}{*}{$\mathrm{P}$ valor } \\
\hline & $1^{\mathrm{s}}$ & $2^{\mathrm{st}}$ & $3^{\text {st }}$ & $4^{\mathrm{st}}$ & $5^{\mathrm{st}}$ & \\
\hline & $\begin{array}{c}\leq 0.48 \\
852\end{array}$ & $\begin{array}{c}0.48-0.52 \\
852\end{array}$ & $\begin{array}{c}0.53-0.56 \\
853\end{array}$ & $\begin{array}{c}0.57-0.60 \\
852\end{array}$ & $\begin{array}{c}>0.61 \\
852\end{array}$ & $<0.0001$ \\
\hline ÍMC (Kg/m²), média (DP) & $22.1(2.5)$ & $24.7(1.8)$ & $26.7(2.0)$ & $28.9(2.3)$ & $33.8(4.3)$ & $<0.0001$ \\
\hline $\begin{array}{l}\text { CC(cm), média (DP) } \\
\text { Diabetes (\%) }\end{array}$ & $\begin{array}{l}74.8(5.8) \\
54(6.3)\end{array}$ & $\begin{array}{l}83.0(4.8) \\
93(10.9)\end{array}$ & $\begin{array}{l}89.2(5.4) \\
138(16.2)\end{array}$ & $\begin{array}{l}95.4(5.8) \\
220(25.8)\end{array}$ & $\begin{array}{l}106.3(9.3) \\
320(37.6)\end{array}$ & $\begin{array}{l}<0.0001 \\
<0.0001\end{array}$ \\
\hline Dislipidemia (\%) & $345(40.5)$ & $491(57.6)$ & $508(59.6)$ & $519(60.9)$ & $539(63.3)$ & $<0.0001$ \\
\hline Hipertensão Arterial (\%) & $104(12.2)$ & $180(21.1)$ & $249(29.2)$ & $320(37.6)$ & $420(49.4)$ & $<0.0001$ \\
\hline PAS (mm/Hg), média (DP) & $112.7(14.6)$ & $116.4(15.1)$ & $119.5(15.6)$ & $122.4(16.2)$ & $125.3(16.4)$ & $<0.0001$ \\
\hline PAD (mm/Hg), média (DP) & $70.3(9.8)$ & $73.0(10.3)$ & $75.0(9.9)$ & $77.1(10.1)$ & $80.4(10.5)$ & $<0.0001$ \\
\hline Atividade Física (\%) & & & & & & $<0.0001$ \\
\hline Inativo & $474(57.5)$ & $492(60.4)$ & $541(65.9)$ & $574(69.3)$ & $624(75.9)$ & \\
\hline Insuficientemente Ativo & $95(11.5)$ & $90(11.0)$ & $101(12.3)$ & $90(10.9)$ & $79(9.6)$ & \\
\hline Ativo & $256(30.9)$ & $233(28.6)$ & $179(21.8)$ & $164(19.8)$ & $119(14.5)$ & \\
\hline Tabagismo $(\%$ & & & & & & $<0.0001$ \\
\hline Nunca & $512(60.1)$ & $474(55.6)$ & $404(47.4)$ & $457(53.6)$ & $438(51.4)$ & \\
\hline Passado & $174(20.4)$ & $229(26.9)$ & $301(35.3)$ & $283(33.2)$ & $309(36.3)$ & \\
\hline Atual & $166(19.5)$ & $149(17.5)$ & $148(17.4)$ & $112(13.1)$ & $105(12.3)$ & \\
\hline Consumo de Álcool (\%) & & & & & & $<0.0001$ \\
\hline Nunca & $97(11.4)$ & $89(10.4)$ & $110(12.9)$ & $105(12.3)$ & $104(12.2)$ & \\
\hline Passado & $171(20.1)$ & $148(17.4)$ & $134(15.7)$ & $189(22.2)$ & $205(24.1)$ & \\
\hline Atual & $584(68.5)$ & $615(72.2)$ & $609(71.4)$ & $558(65.5)$ & $543(63.7)$ & \\
\hline EIMC, média (DP) & $0.55(0.10)$ & $0.58(0.12)$ & $0.61(0.12)$ & $0.63(0.14)$ & $0.6590 .14)$ & $<0.0001$ \\
\hline EIMC $\geq$ P75 (\%) & $130(15.3)$ & $206(24.2)$ & $297(34.8)$ & $312(36.6)$ & $399(46.8)$ & $<0.0001$ \\
\hline Escore de Cálcio (CAC) & $0(0-0)$ & $0(0-0)$ & $0(0-8)$ & $0(0-12)$ & $0(0-20)$ & $<0.001$ \\
\hline $\mathrm{CAC}>\mathrm{O}(\%)$ & $139(16,3)$ & $205(24,1)$ & $263(30,8)$ & $282(33,1)$ & $303(35,6)$ & $<0.000$ \\
\hline $\mathrm{CAC} \geq 100(\%)$ & $49(5,8)$ & $50(5,9)$ & $86(10,1)$ & $97(11,4)$ & $116(13,6)$ & $<0.000$ \\
\hline
\end{tabular}


O estudo envolveu 4261 indivíduos (1940 homens e 2321 mulheres com idade média de 50,7 (+/- 8,7 anos). A tabela 1 descreve as características sociodemográficas da amostra, segundo os quintis da relação cintura-estatura (RCE). Observamos nos últimos quintis uma menor frequência de brancos $(\mathrm{p}<0,0001)$ e de indivíduos com ensino superior completo $(\mathrm{p}<0,0001)$. Considerando as variáveis clínicas da amostra na Tabela 2, nos últimos quintis ocorre maior presença de fatores de risco cardiovascular (maiores médias de IMC e maiores porcentagens de diabetes, dislipidemia, além de menor prática de atividade física $(\mathrm{p}<0,0001)$. Observando a presença de aterosclerose subclínica pelo $\mathrm{CAC}$, indivíduos com $\mathrm{CAC}>0$ e com $\mathrm{CAC} \geq 100$ estão em maior magnitude nos quintis mais elevados de RCE ( $<<0,0001)$ (Figuras 6 e 7).

Figura 6 - Presença de CAC >0 nos grupos divididos conforme os quintis de RCE.

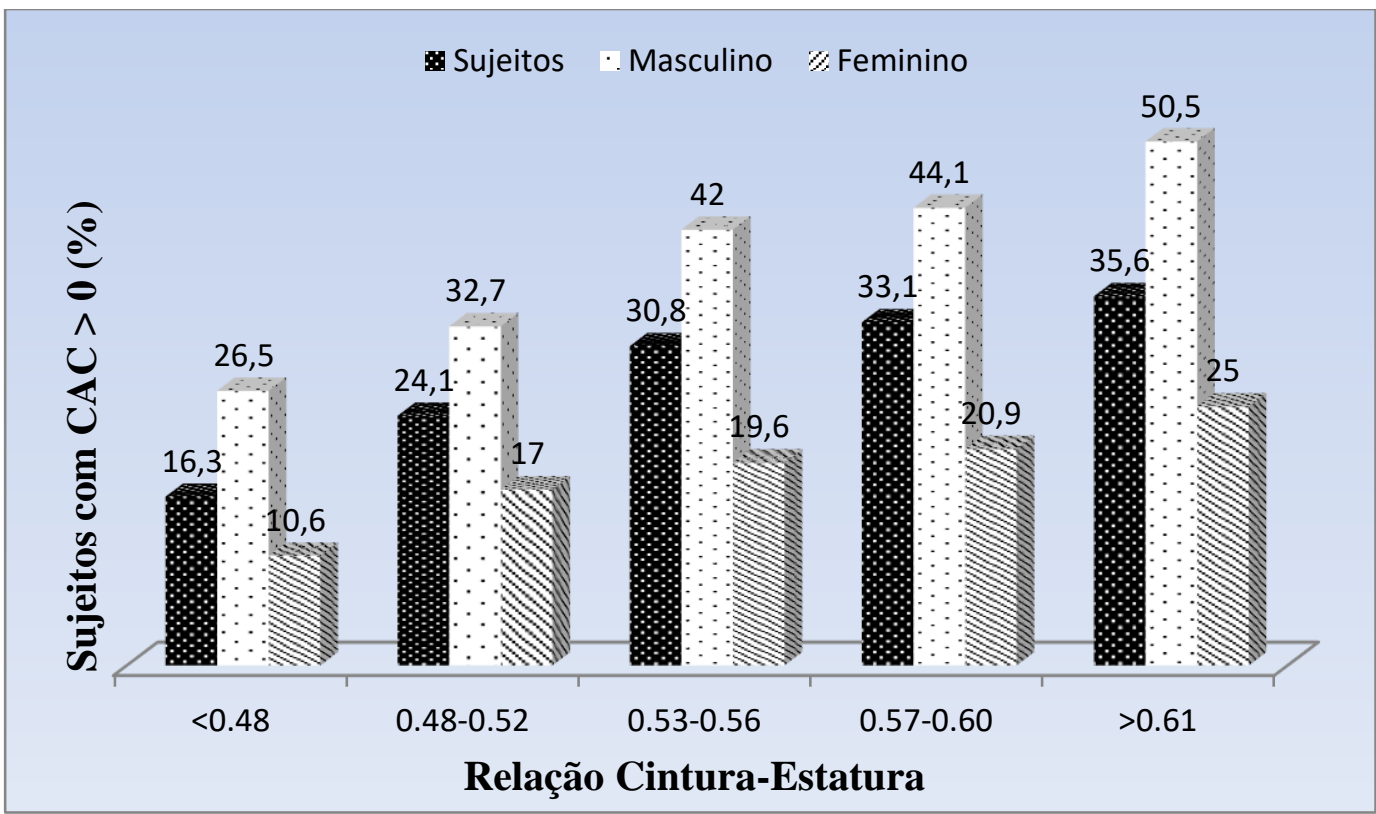


Figura 7 - Presença de $C A C \geq 100$ nos grupos divididos conforme os quintis de RCE

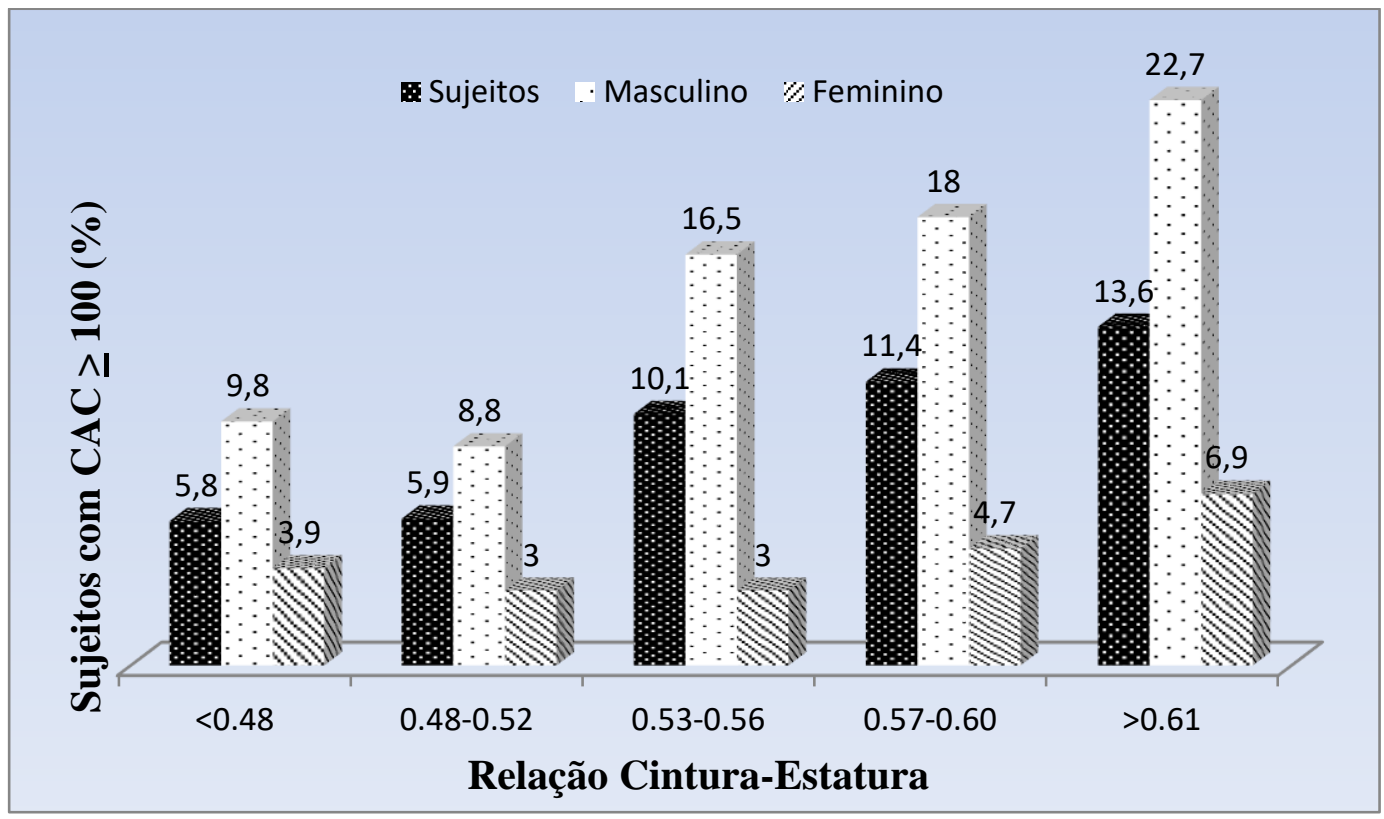

Comportamento semelhante observou com a presença de aterosclerose subclínica pelo EIMC $\geq P 75$, com maior concentração da amostra nos quintis mais elevados de RCE (Figura 8).

Figura 8 - Presença de EIMC $\geq$ P75 nos grupos divididos conforme os quintis de RCE.

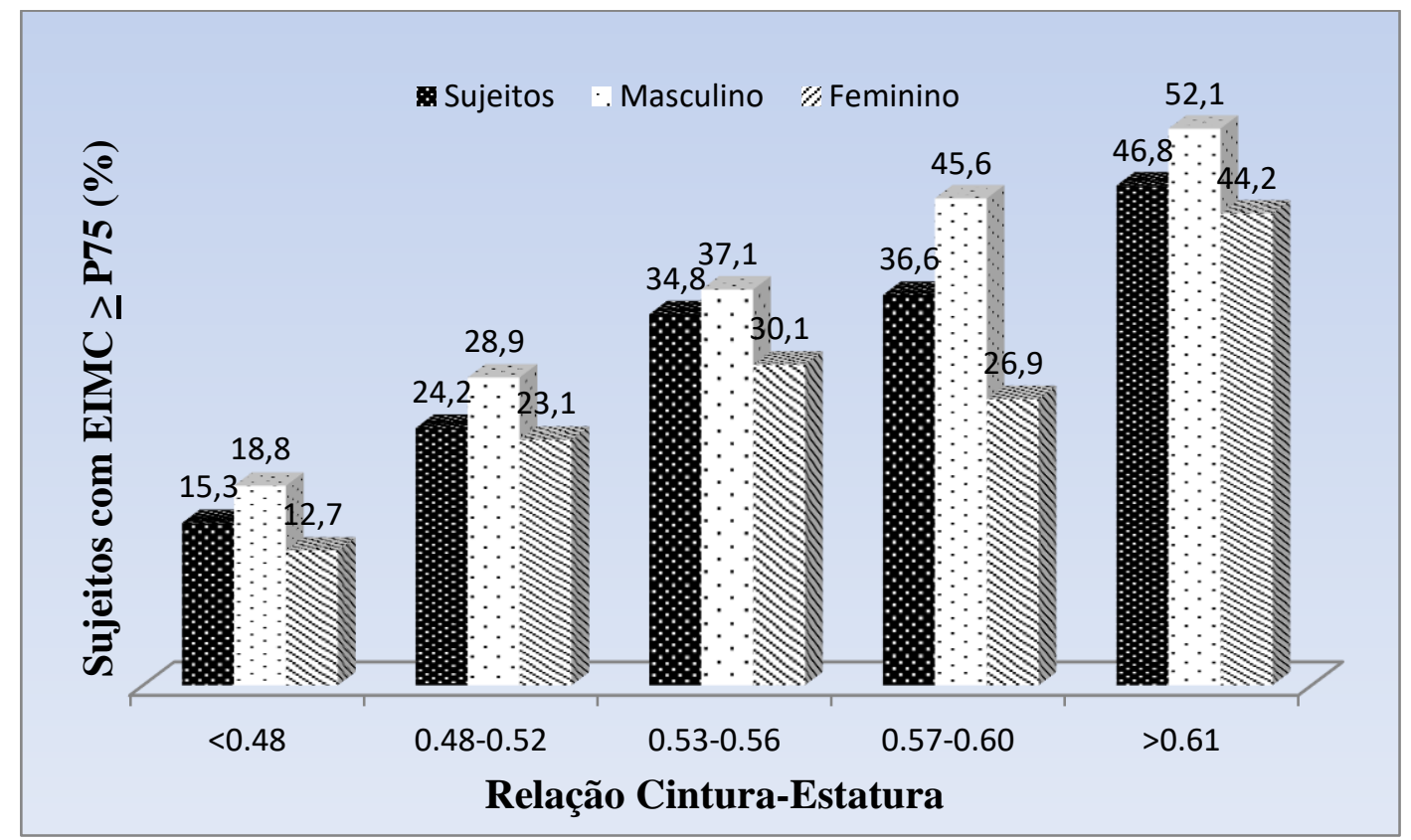


A tabela 3 demonstra as condições sociodemográficas nos homens, onde os quintis mais altos da relação cintura-estatura apresentam as maiores médias de idade $(\mathrm{p}<0,0001)$, maior frequência de pessoas de cor branca $(\mathrm{p}<0,0001)$ e de maior renda familiar mensal média ( $\mathrm{p}<0,0001)$. Além disso, apresentam-se menos ativos $(\mathrm{p}<0,0001)$ e com um perfil de fatores de risco cardiovasculares (diabetes, dislipidemia, hipertensão arterial) menos saudável $(\mathrm{p}<0,0001)$. Ainda na amostra masculina, a maior porcentagem dos homens com CAC $>0$, com $C A C \geq 100$ e com EIMC $\geq P 75$ está presente nos últimos quintis de RCE (Tabela 4). 
Tabela 3 - Características sociodemográficas da amostra no sexo masculino.

\begin{tabular}{|c|c|c|c|c|c|c|}
\hline \multirow[b]{2}{*}{ Quintis } & \multicolumn{5}{|c|}{ Quintis da Relação Cintura-Estatura } & \multirow[b]{2}{*}{$\begin{array}{l}P \text { valor } \\
<0.0001\end{array}$} \\
\hline & $\begin{aligned} & 1^{\text {st }} \\
\leq & 0.48 \\
& 388\end{aligned}$ & $\begin{array}{l}2^{\text {st }} \\
0.48-0.52 \\
388\end{array}$ & $\begin{array}{c}3^{\mathrm{st}} \\
0.53=0.56 \\
388\end{array}$ & $\begin{array}{c}4^{\mathrm{st}} \\
0.57-0.60 \\
388\end{array}$ & $\begin{array}{c}5^{\text {st }} \\
>0.61 \\
388\end{array}$ & \\
\hline Idade (anos) & $47.9(8.8)$ & $49.9(8.5)$ & $50.5(8.5)$ & $52.4(9.3)$ & $53.0(9.3)$ & $<0.0001$ \\
\hline $\operatorname{Raça}(\%)$ & & & & & & $<0.0001$ \\
\hline $\begin{array}{l}\text { Brancos } \\
\text { Pardos } \\
\text { Pretos }\end{array}$ & $\begin{array}{c}214(55.4) \\
103(26.7) \\
49(12.7)\end{array}$ & $\begin{array}{l}223(58.8) \\
91(24.0) \\
49(12.9)\end{array}$ & $\begin{array}{l}216(56.8) \\
88(23.2) \\
56(14.7)\end{array}$ & $\begin{array}{l}207(54.8) \\
91(24.1) \\
61(16.1)\end{array}$ & $\begin{array}{l}232(60.3) \\
103(26.8) \\
39(10.1)\end{array}$ & \\
\hline $\begin{array}{l}\text { Asiáticos } \\
\text { Indígenos }\end{array}$ & $\begin{array}{c}18(4.7) \\
2(0.5)\end{array}$ & $\begin{array}{c}12(3.2) \\
4(1.1)\end{array}$ & $\begin{array}{c}14(3.7) \\
6(1.6)\end{array}$ & $\begin{array}{c}9(2.4) \\
10(2.6)\end{array}$ & $\begin{array}{l}5(1.3) \\
6(1.6)\end{array}$ & \\
\hline Nível Educacional (\%) & & & & & & $<0.0001$ \\
\hline $\begin{array}{l}\text { Ensino Fundamental } \\
\text { Ensino Médio e Superior Incompleto } \\
\text { Ensino Completo ou Pós-graduação }\end{array}$ & $\begin{array}{l}70(18.0) \\
177(45.6) \\
141(36.3)\end{array}$ & $\begin{array}{l}73(18.8) \\
156(40.2) \\
159(41.0)\end{array}$ & $\begin{array}{l}59(15.2) \\
162(41.8) \\
167(43.0)\end{array}$ & $\begin{array}{l}92(23.7) \\
150(38.7) \\
146(37.6)\end{array}$ & $\begin{array}{l}88(22.7) \\
158(40.7) \\
142(36.6)\end{array}$ & \\
\hline Renda mensal media familiar $(\%)$ & & & & & & $<0.0001$ \\
\hline $\begin{array}{l}\leq \mathrm{R} \$ 2490,00 \\
\mathrm{R} \$ 2491,00 \text { a } \mathrm{R} \$ 6638,00 \\
\geq \mathrm{R} \$ 6639,00\end{array}$ & $\begin{array}{c}165(42.7) \\
127(32.9) \\
94(24.4)\end{array}$ & $\begin{array}{l}134(34.5) \\
134(34.5) \\
120(30.9)\end{array}$ & $\begin{array}{l}125(32.6) \\
136(35.4) \\
123(32.0)\end{array}$ & $\begin{array}{l}143(37.1) \\
116(30.1) \\
126(32.7)\end{array}$ & $\begin{array}{l}125(32.3) \\
140(36.2) \\
122(31.5)\end{array}$ & \\
\hline
\end{tabular}


Tabela 4 - Características clínicas da amostra no sexo masculino.

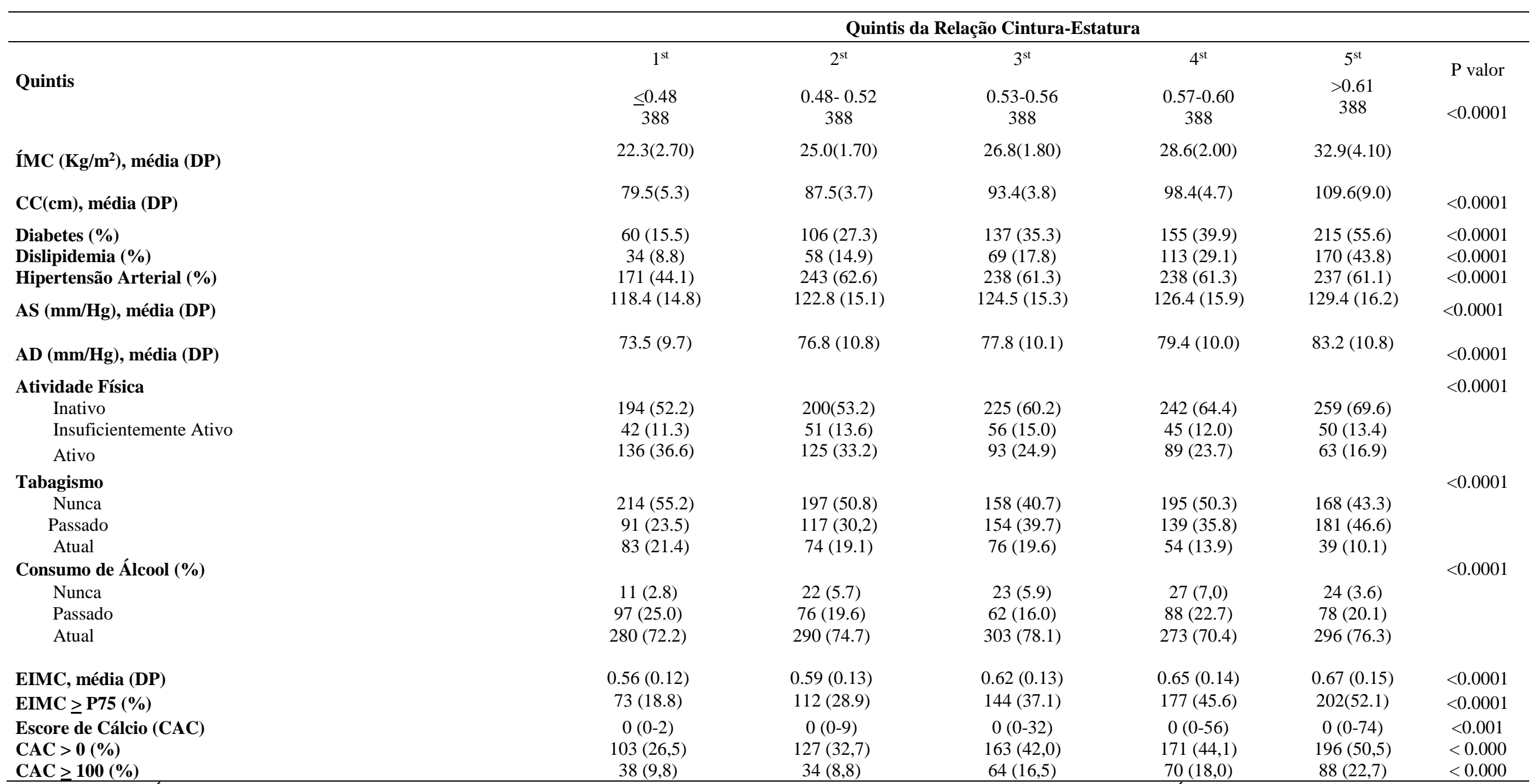

IMC, Índice de Massa Corporal; CC, Circunferência da Cintura; PAS, Pressão Arterial Sistólica; PAD, Pressão Arterial Diastólica; EIMC, Espessura Íntima Media Carótida; DP, desvio padrão 
Já na tabela 5, as mulheres também apresentam nos quintis mais altos da relação cintura-estatura as maiores médias de idade $(\mathrm{p}<0,0001)$, porém com menor frequência com ensino superior completo $(\mathrm{p}<0,0001)$ e diferentemente dos homens com menor renda familiar mensal média ( $\mathrm{p}<0,0001)$. São menos ativas $(\mathrm{p}<0,0001)$, com maiores médias de IMC ( $\mathrm{p}<0,0001)$ e perfil menos saudável de fatores de risco cardiovascular (diabetes, dislipidemia e hipertensão arterial) $(\mathrm{p}<0,0001)$ (Tabela 6).

As mulheres nos quintis mais elevados de RCE também apresentaram proporções mais levadas de $\mathrm{CAC}>0, \mathrm{CAC} \geq 100$, e de $\mathrm{EIMC} \geq \mathrm{P} 75 \%(\mathrm{p}<0,001)$. 
Tabela 5 - Características sociodemográficas da amostra no sexo feminino.

\begin{tabular}{|c|c|c|c|c|c|c|}
\hline & \multicolumn{4}{|c|}{ Quintis da Relação Cintura-Estatura } & & \multirow[b]{2}{*}{$\begin{array}{l}\text { P valor } \\
<0.0001\end{array}$} \\
\hline Quintis & $\begin{array}{l}1^{\text {st }} \\
\leq 0.48 \\
464\end{array}$ & $\begin{array}{c}2^{\text {st }} \\
0.48-0.52 \\
464\end{array}$ & $\begin{array}{c}3^{\text {st }} \\
0.53-0.56 \\
465\end{array}$ & $\begin{array}{c}4^{\mathrm{st}} \\
0.57=0.60 \\
464\end{array}$ & $\begin{array}{c}5^{\mathrm{st}} \\
>0.61 \\
464\end{array}$ & \\
\hline Idade (anos) & $47.64(8.2)$ & $48.87(7.8)$ & $50.90(8.1)$ & $51.30(8.3)$ & $53.37(8.8)$ & $<0.0001$ \\
\hline Raça (\%) & & & & & & $<0.0001$ \\
\hline $\begin{array}{l}\text { Brancos } \\
\text { Pardos } \\
\text { Pretos } \\
\text { Asiáticos } \\
\text { Indígenos }\end{array}$ & $\begin{array}{c}303(65.9) \\
65(14.1) \\
55(12,0) \\
35(7.6) \\
2(0.4)\end{array}$ & $\begin{array}{c}285(61.7) \\
86(18.6) \\
53(11.5) \\
34(7.4) \\
4(0.9)\end{array}$ & $\begin{array}{c}266(58.1) \\
94(20.5) \\
68(14.8) \\
29(6.3) \\
1(0.2)\end{array}$ & $\begin{array}{c}274(59.7) \\
106(23.1) \\
60(13.1) \\
15(3.3) \\
4(0.9)\end{array}$ & $\begin{array}{c}251(54.7) \\
96(20.9) \\
95(20.7) \\
12(2.6) \\
5(1.1)\end{array}$ & \\
\hline Nível Educacional (\%) & & & & & & $<0.0001$ \\
\hline $\begin{array}{l}\text { Ensino Fundamental } \\
\text { Ensino Médio e Superior Incompleto } \\
\text { Ensino Superior Completo ou Pós-graduação }\end{array}$ & $\begin{array}{c}14(3,0) \\
148(31.9) \\
302(65.1)\end{array}$ & $\begin{array}{c}24(5.2) \\
187(40.3) \\
253(54.5)\end{array}$ & $\begin{array}{c}46(9.9) \\
205(44.1) \\
214(46.0)\end{array}$ & $\begin{array}{c}61(13.1) \\
212(45.7) \\
191(41.2)\end{array}$ & $\begin{array}{c}96(20.7) \\
212(45.7) \\
156(33.6)\end{array}$ & \\
\hline Renda mensal media familiar (\%) & & & & & & $<0.0001$ \\
\hline $\begin{array}{l}\leq \mathrm{R} \$ 2490,00 \\
\mathrm{R} \$ 2491,00 \text { a } \mathrm{R} \$ 6638,00 \\
\geq \mathrm{R} \$ 6639,00\end{array}$ & $\begin{array}{c}98(21.3) \\
202(43.8) \\
161(34.9)\end{array}$ & $\begin{array}{l}99(21.4) \\
200(43.2) \\
164(35.4)\end{array}$ & $\begin{array}{l}126(27.2) \\
209(45.1) \\
128(27.6)\end{array}$ & $\begin{array}{l}161(34.7) \\
176(37.9) \\
127(27.4)\end{array}$ & $\begin{array}{l}171(37.1) \\
189(41.0) \\
101(21.9)\end{array}$ & \\
\hline
\end{tabular}


Tabela 6 - Características clínicas da amostra no sexo feminino.

\begin{tabular}{|c|c|c|c|c|c|c|}
\hline \multicolumn{6}{|c|}{ Quintis da Relação Cintura-Estatura } & \multirow{3}{*}{ P Valor } \\
\hline \multirow{3}{*}{ Quintis } & $1^{\mathrm{st}}$ & $2^{\mathrm{st}}$ & $3^{\text {st }}$ & $4^{\mathrm{st}}$ & $5^{\text {st }}$ & \\
\hline & $\leq 0.48$ & $0.48-0.52$ & $0.53 \_0.56$ & $0.57 \_0.60$ & $>0.61$ & \\
\hline & 464 & 464 & 465 & 464 & 464 & $<0.0001$ \\
\hline ÍMC (Kg/m²), média (DP) & $21.9(2.24)$ & $24.5(1.87)$ & $26.6(2.16)$ & $29.3(2.46)$ & $34.4(4.47)$ & \\
\hline CC(cm), média (DP) & $71.8(4.5)$ & $79.6(3.5)$ & $84.9(4.1)$ & $91.4(4.6)$ & $104.1(9.3)$ & $<0.0001$ \\
\hline Diabetes $(\%)$ & $48(10.3)$ & $78(16.8)$ & $110(23.7)$ & $152(32.8)$ & $212(45.7)$ & $<0.0001$ \\
\hline Dislipidemia (\%) & $21(4.5)$ & $41(8.8)$ & $63(13.5)$ & $99(21.3)$ & $157(33.8)$ & $<0.0001$ \\
\hline Hipertensão Arterial (\%) & $170(36.6)$ & $250(53.9)$ & $275(59.1)$ & $280(60.3)$ & $300(64.7)$ & $<0.0001$ \\
\hline PAS (mm/Hg), média (DP) & $109.3(13.1)$ & 110.9.3 (13.6) & $114.9(14.3)$ & $117.2(14.5)$ & $122.8(16.4)$ & $<0.0001$ \\
\hline PAD (mm/Hg), média (DP) & $68.4(9.5)$ & $69.9(9.2)$ & $72.4(8.9)$ & $74.3(9.2)$ & $78.4(10.0)$ & $<0.0001$ \\
\hline Atividade Física & & & & & & $<0.0001$ \\
\hline Inativo & $271(59.8)$ & $291(66.4)$ & $323(72.3)$ & $334(74.4)$ & $366(80.8)$ & \\
\hline Insuficientemente Ativo & $51(11.3)$ & $48(11.0)$ & $39(8.7)$ & $43(9.6)$ & $30(6.6)$ & \\
\hline Ativo & $131(28.9)$ & 99 (22.6) & $85(19.0)$ & $72(16.0)$ & $57(12.6)$ & \\
\hline Tabagismo & & & & & & $<0.0001$ \\
\hline Nunca & $302(65.1)$ & $266(57.3)$ & $252(54.2)$ & $273(58.8)$ & $260(56.0)$ & \\
\hline Passado & $82(17.7)$ & $124(26.7)$ & $137(29.5)$ & $133(28.7)$ & $138(29.7)$ & \\
\hline Atual & $80(17.2)$ & $74(15.9)$ & $76(16.3)$ & $58(12.5)$ & $66(14.2)$ & \\
\hline Consumo de Álcool (\%) & & & & & & $<0.0001$ \\
\hline Nunca & $78(16.8)$ & $70(15.1)$ & $92(19.8)$ & $83(17.9)$ & $85(18.3)$ & \\
\hline Passado & $71(15.3)$ & $77(16.6)$ & $72(15.5)$ & $98(21.1)$ & $128(27.6)$ & \\
\hline Atual & $315(67.9)$ & $317(68.3)$ & $301(64.7)$ & $283(61.0)$ & $251(63)$. & \\
\hline EIMC, média (DP) & $0.54(0.09)$ & $0.57(0.11)$ & $0.59(0.12)$ & $0.59(0.11)$ & $0.64(0.14)$ & $<0.0001$ \\
\hline EIMC $\geq$ P75 $(\%)$ & $59(12.7)$ & $107(23.1)$ & $140(30.1)$ & $125(26.9)$ & 205 (44.2.) & $<0.0001$ \\
\hline Escore de Cálcio (CAC) & $0(0-0)$ & $0(0-0)$ & $0(0-0)$ & $0(0-0)$ & $0(0-0.5)$ & $<0.001$ \\
\hline $\mathrm{CAC}>0(\%)$ & $49(10.6)$ & $79(17.0)$ & $91(19.6)$ & $97(20.9)$ & $116(25.0)$ & $<0.000$ \\
\hline $\mathrm{CAC} \geq 100(\%)$ & $18(3.9)$ & $14(3.0)$ & $18(3.9)$ & $22(4.7)$ & $32(6.9)$ & $<0.000$ \\
\hline
\end{tabular}

IMC, Índice de Massa Corporal; CC, Circunferência da Cintura; PAS, Pressão Arterial Sistólica; PAD, Pressão Arterial Diastólica; EIMC, Espessura Íntima Media Carótida; DP, desvio padrão 
A Tabela 7 apresenta os resultados dos modelos de regressão logística para avaliar os efeitos dos quintis da relação cintura-estatura sobre o CAC (para CAC>0 e CAC $\geq 100$ ), cujos efeitos estão apresentados na forma de razão de chances e respectivos intervalos de confiança de 95\% (IC95\%). Observa-se no modelo ajustado por fatores de risco sociodemográficos e cardiovasculares (modelo 2) uma razão de chance no último quintil respectivamente de 1,68 (IC95\%: 1,26-2,25) para CAC>0; e 1,36 (IC95\%: 0,89-2,09) para $\mathrm{CAC} \geq 100$ utilizando-se o primeiro quintil como referência.

As tabelas 8 e 9 apresentam a regressão logística realizada conforme o sexo. Nos homens (Tabela 8) houve associação para CAC > 0 e sem associação para CAC $\geq 100$ quando ajustado por fatores de risco sociodemográficos e cardiovasculares (modelo 2). Nas mulheres (Tabela 9), não houve associação da medida da relação cintura-estatura, tanto com $\mathrm{CAC}>0$ quanto com $\mathrm{CAC} \geq 100$ a partir do ajuste pelas variáveis sociodemográficas. 
Tabela 7 - Razões de Chances (com intervalo de confiança de 95\%) da Associação dos Quintis da Relação Cintura- Estatura (RCE) com o CAC na amostra.

\begin{tabular}{lccc}
\hline & Referência & Modelo 1 & Modelo 2 \\
\hline CAC > 0 & & & \\
$1^{\text {st }}$ & 1.0 (Referência) & 1.0 (Referência) & 1.0 (Referência) \\
$2^{\text {nd }}$ & $1.63(1.28-2.07)$ & $1.35(1.03-1.77)$ & $1.25(0.95-1.66)$ \\
$3^{\text {rd }}$ & $2.29(1.81-2.89)$ & $1.65(1.26-2.15)$ & $1.57(1.19-2.07)$ \\
$4^{\text {th }}$ & $2.54(2.01-3.20)$ & $1.67(1.27-2.18)$ & $1.54(1.16-2.04)$ \\
$5^{\text {th }}$ & $2.83(2.25-3.56)$ & $1.89(1.45-2.48)$ & $1.68(1.26-2.25)$ \\
& & & \\
$\mathbf{C A C}^{\text {s. } \mathbf{1 0 0}}$ & & $1.0($ Referência) & $1.0($ Referência) \\
$1^{\text {st }}$ & $1.0($ Referência) & $0.79(0.51-1.24)$ & $0.75(0.48-1.18)$ \\
$2^{\text {nd }}$ & $0.95(0.63-1.43)$ & $1.27(0.85-1.90)$ & $1.07(0.71-1.63)$ \\
$3^{\text {rd }}$ & $1.61(1.11-2.33)$ & $1.26(0.85-1.88)$ & $1.12(0.73-1.70)$ \\
$4^{\text {th }}$ & $1.79(1.25-2.58)$ & $1.72(1.16-2.54)$ & $1.36(0.89-2.09)$ \\
$5^{\text {th }}$ & $2.62(1.84-3.74)$ & & \\
\hline
\end{tabular}

Modelo 1: ajustado para idade, sexo, raça, nível educacional; Modelo 2: Modelo 1 ajustado com variáveis de hipertensão, diabetes, dislipidemia, tabagismo, consumo de álcool e prática de atividade física no lazer 
Tabela 8 - Razões de Chances (com intervalo de confiança de 95\%) da Associação dos Quintis da Relação Cintura- Estatura (RCE) com a presença de CAC na amostra no sexo masculino.

\begin{tabular}{lccc}
\hline & Referência & Modelo 1 & Modelo 2 \\
\hline CAC > 0 & & & \\
$1^{\text {st }}$ & 1.0 (Referência) & 1.0 (Referência) & 1.0 (Referência) \\
$2^{\text {nd }}$ & $1.35(0.99-1.84)$ & $1.15(0.81-1.62)$ & $1.05(0.73-1.50)$ \\
$3^{\text {rd }}$ & $2.00(1.48-2.71)$ & $1.73(1.23-2.42)$ & $1.67(1.17-2.38)$ \\
$4^{\text {th }}$ & $2.18(1.61-2.95)$ & $1.65(1.17-2.32)$ & $1.51(1.05-2.16)$ \\
$5^{\text {th }}$ & $2.83(2.09-3.82)$ & $1.99(1.41-2.79)$ & $1.74(1.19-2.54)$
\end{tabular}

$\begin{array}{llll}\mathbf{C A C} \geq \mathbf{1 0 0} & & & \\ 1^{\text {st }} & 1.0 \text { (Referência) } & 1.0 \text { (Referência) } & 1.0 \text { (Referência) } \\ 2^{\text {nd }} & 0.88(0.54-1.44) & 0.75(0.44-1.28) & 0.68(0.40-1.18) \\ 3^{\text {rd }} & 1.82(1.19-2.79) & 1.57(0.98-2.52) & 1.34(0.81-2.21) \\ 4^{\text {th }} & 2.03(1.33-3.10) & 1.50(0.94-2.39) & 1.33(0.80-2.19) \\ 5^{\text {th }} & 2.70(1.79-4.07) & 1.88(1.19-2.97) & 1.43(0.86-2.37)\end{array}$

Modelo 1: ajustado para idade, sexo, raça, nível educacional; Modelo 2: Modelo 1 ajustado com variáveis de hipertensão, diabetes, dislipidemia, tabagismo, consumo de álcool e prática de atividade física no lazer 
Tabela 9 - Razões de Chances (com intervalo de confiança de 95\%) da Associação dos Quintis da Relação Cintura- Estatura (RCE) com a presença de CAC na amostra no sexo feminino.

\begin{tabular}{lrrr}
\hline & Referência & Modelo 1 & Modelo 2 \\
\hline CAC $>\mathbf{0}$ & & & \\
$1^{\text {st }}$ & 1.0 (Reference) & 1.0 (Reference) & 1.0 (Reference) \\
$2^{\text {nd }}$ & $1.74(1.19-2.55)$ & $1.51(0.98-2.30)$ & $1.48(0.95-2.32)$ \\
$3^{\text {rd }}$ & $2.06(1.42-3.00)$ & $1.47(0.96-2.24)$ & $1.39(0.89-2.17)$ \\
$4^{\text {th }}$ & $2.24(1.54-3.24)$ & $1.57(1.03-2.40)$ & $1.49(0.95-2.33)$ \\
$5^{\text {th }}$ & $2.82(1.96-4.06)$ & $1.54(1.00-2.35)$ & $1.36(0.86-2.16)$
\end{tabular}

\section{$\mathrm{CAC} \geq 100$}

$\begin{array}{llll}1^{\text {st }} & 1.0 \text { (Referência) } & 1.0 \text { (Referência) } & 1.0 \text { (Referência) } \\ 2^{\text {nd }} & 0.77(0.38-1.57) & 0.65(0.31-1.37) & 0.65(0.30-1.39) \\ 3^{\text {rd }} & 1.00(0.51-1.94) & 0.75(0.37-1.54) & 0.64(0.31-1.34) \\ 4^{\text {th }} & 1.23(0.65-2.33) & 0.91(0.45-1.82) & 0.84(0.41-1.73) \\ 5^{\text {th }} & 1.84(1.02-3.32) & 1.06(0.55-2.08) & 0.87(0.42-1.79)\end{array}$

Modelo 1: ajustado para idade, sexo, raça, nível educacional; Modelo 2: Modelo 1 ajustado com variáveis de hipertensão, diabetes, dislipidemia, tabagismo, consumo de álcool e prática de atividade física no lazer. 
A Tabela 10 mostra os modelos de regressão logística e linear para a associação dos quintis da relação cintura-estatura com EIMC na amostra geral. Para EIMC $\geq$ P75, após o ajuste por fatores de risco sociodemográficos e cardiovasculares (modelo 2) observou-se uma razão de chances no quintil mais elevado de 2,75 (IC95\%: 2,08-3,63), utilizando-se o primeiro quintil como referência. Nos homens (Tabela 11), para EIMC $\geq$ P75, observou-se uma razão de chances de 2,95 (IC95\%: 1,99-4,35) e nas mulheres (Tabela 12) de 2,73 (IC95\%: 1,81-4,10) após ajuste por fatores sociodemográficos e cardiovasculares.

No modelo de regressão linear, a relação cintura-estatura mostrou associação significativa com o EIMC nos modelos ajustados por variáveis sociodemográficas e por fatores de risco cardiovasculares (modelo 2) com razão de chances de 0,22 (IC95\%: 0,170,27) com comportamento semelhante nos homens e nas mulheres com associação positiva da relação cintura-estatura com EIMC: RC de 0,29 (IC95\%: 0,20-0,38) nos homens e 0,18 (IC95\%: 0,12-0,24) nas mulheres. (Tabelas 11 e 12). 
Tabela 10 - Razões de Chances e efeitos (com intervalo de confiança de 95\%) da associação dos Quintis da Relação Cintura- Estatura (RCE) com a EIMC $>$ P75 na amostra.

\begin{tabular}{lccc}
\hline & \multicolumn{2}{c}{ Modelos de Regressão Logística } & \\
& Referência & Modelo 1 & Modelo 2 \\
\hline EIMC $\geq$ P75 & & & \\
$1^{\text {st }}$ quintile & 1.0 (Referência) & 1.0 (Referência) & 1.0 (Referência) \\
$2^{\text {nd }}$ quintile & $1.77(1.39-2.26)$ & $1.51(1.15-1.98)$ & $1.47(1.11-1.94)$ \\
$3^{\text {rd }}$ quintile & $2.97(2.35-3.75)$ & $2.30(1.77-2.98)$ & $2.13(1.63-2.79)$ \\
$4^{\text {th }}$ quintile & $3.21(2.54-4.05)$ & $2.24(1.72-2.91)$ & $2.01(1.53-2.65)$ \\
$5^{\text {th }}$ quintile & $4.89(3.89-6.16)$ & $3.35(2.59-4.34)$ & $2.75(2.08-3.63)$ \\
& & & \\
\hline
\end{tabular}

\section{Modelos lineares multivariados para EIMC}

\begin{tabular}{cccc}
\hline & Referência & Modelo 1 & Modelo 2 \\
RCE & 0.47 & 0.28 & 0.22 \\
& $(0.42 \mathrm{a} 0.52)$ & $(0.23$ a 0.32$)$ & $(0.17 \mathrm{a} 0.27)$ \\
\hline
\end{tabular}

Modelo1: ajustado para idade, sexo, raça, nível educacional; Modelo 2: Modelo 1 ajustado com variáveis de hipertensão, diabetes, dislipidemia, tabagismo, consumo de álcool e atividade física 
Tabela 11 - Razões de Chances e efeitos (com intervalo de confiança de 95\%) da associação dos Quintis da Relação Cintura- Estatura (RCE) com a EIMC $\geq$ P75 no sexo masculino.

\begin{tabular}{lccc}
\hline \multicolumn{4}{c}{ Modelos de Regressão Logística } \\
& Referência & Modelo 1 & Modelo 2 \\
\hline EIMC $\geq$ P75 & & & \\
$1^{\text {st }}$ quintile & 1.0 (Referência) & 1.0 (Referência) & 1.0 (Referência) \\
$2^{\text {nd }}$ quintile & $1.75(1.25-2.45)$ & $1.60(1.11-2.31)$ & $1.45(0.99-2.12)$ \\
$3^{\text {rd }}$ quintile & $2.55(1.84-3.53)$ & $2.26(1.58-3.25)$ & $2.00(1.37-2.91)$ \\
$4^{\text {th }}$ quintile & $3.62(2.62-5.00)$ & $2.82(1.97-4.04)$ & $2.51(1.72-3.65)$ \\
$5^{\text {th }}$ quintile & $4.69(3.39-6.48)$ & $3.70(2.59-5.29)$ & $2.95(1.99-4.35)$ \\
& & & \\
\hline & Modelos lineares multivariados para EIMC & \\
& & & Modelo 2 \\
& Referência & Modelo 1 & 0.29 \\
RCE & 0.54 & 0.36 & $(0.20$ a 0.38)
\end{tabular}

Modelo 1: ajustado para idade, sexo, raça, nível educacional; Modelo 2: Modelo 1 ajustado com variáveis de hipertensão, diabetes, dislipidemia, tabagismo, consumo de álcool e atividade física. 
Tabela 12 - Razões de Chances e efeitos (com intervalo de confiança de 95\%) da associação dos Quintis da Relação Cintura- Estatura (RCE) com a EIMC $\geq P 75$ no sexo feminino.

\begin{tabular}{lccc}
\hline \multicolumn{4}{c}{ Modelos de Regressão Logística } \\
& Referência & Modelo 1 & Modelo 2 \\
\hline EIMC $\geq$ P75 & & & \\
$1^{\text {st }}$ quintile & 1.0 (Referência) & 1.0 (Referência) & 1.0 (Referência) \\
$2^{\text {nd }}$ quintile & $2.06(1.45-2.91)$ & $1.80(1.22-2.65)$ & $1.79(1.19-2.69)$ \\
$3^{\text {rd }}$ quintile & $2.96(2.11-4.14)$ & $2.26(1.54-3.31)$ & $2.12(1.42-3.16)$ \\
$4^{\text {th }}$ quintile & $2.53(1.80-3.56)$ & $1.79(1.21-2.64)$ & $1.58(1.05-2.38)$ \\
$5^{\text {th }}$ quintile & $5.43(3.91-7.55)$ & $3.53(2.29-4.90)$ & $2.73(1.81-4,10)$ \\
\end{tabular}

Modelos lineares multivariados para EIMC

\begin{tabular}{cccc}
\hline & Referência & Modelo 1 & Modelo 2 \\
RCE & 0.43 & 0.2 & 0.18 \\
& $(0.37$ a 0.49$)$ & $(0.17$ a 0.28$)$ & $(0.12$ a 0.24$)$ \\
\hline
\end{tabular}

Modelo 1: ajustado para idade, sexo, raça, nível educacional; Modelo 2: Modelo 1 ajustado com variáveis de hipertensão, diabetes, dislipidemia, tabagismo, consumo de álcool e atividade física 


\section{DISCUSSÃO}

Os resultados mostram que neste estudo a Relação Cintura-Estatura (RCE) está associada à aterosclerose subclínica mensurada pelo Escore de Cálcio Coronariano (CAC) e pela EIMC após ajuste para fatores sociodemográficos e fatores de risco cardiovasculares.

Há dois estudos na literatura internacional que avaliaram a associação entre a RCE e a aterosclerose subclínica medida pelo CAC com delineamento prospectivo (Kramer et al., 2009; Oh et al., 2016).

O estudo de Kramer et al., mostrou a associação de diversas medidas antropométricas (circunferência da cintura, relação cintura-quadril e relação cinturaestatura), e de gordura visceral e subcutânea (medida pela tomografia computadorizada), com a progressão de CAC em 156 homens e 182 mulheres com idade média de 67 anos após 4,5 anos de acompanhamento. O estudo mostrou uma associação da relação cinturaestatura ( $\geq 0.55$ para homens e $\geq 0.54$ para mulheres) com progressão de CAC após ajuste por idade, glicemia de jejum e pressão arterial sistólica $(\mathrm{p}=0,03)$. O estudo também mostrou uma associação da relação cintura-quadril com progressão de CAC, entretanto, nenhuma relação foi encontrada entre índice de massa corporal e circunferência da cintura com a progressão desta medida de aterosclerose subclínica. O estudo avaliou a associação da relação cintura-estatura com a progressão de CAC de acordo com o sexo, e a única associação encontrada por sexo foi da circunferência da cintura em mulheres com a progressão de CAC. Entretanto, é pouco provável que a amostra pequena tenha poder de análise (Kramer et al., 2009). 
Outro estudo prospectivo, avaliou a associação da RCE e a progressão de CAC em 1048 homens coreanos com idade média em torno de 41 anos após seguimento de 4 anos, onde a progressão de CAC foi definida como qualquer aumento do valor ao longo de 4 anos. Durante o seguimento, ocorreu progressão de CAC em 278 participantes (26.5\%). Os indivíduos com progressão de CAC apresentaram um valor basal da RCE ligeiramente superior aos que não apresentaram progressão, com $0,51(0,04)$ vs. 0,50 $(0,04)(\mathrm{p}<0,01)$. Quando houve a divisão em quartis, a proporção de indivíduos com progressão de CAC aumentou à medida que a RCE também aumentou (do $1^{\circ}$ ao $4^{\circ}$ quartil de $18,3 \%, 18,7 \%, 28,8 \%$ e $34,2 \%$. O risco de progressão de CAC foi elevado com uma razão de chances de 1,60 (IC95\% 1.04-2,47) no quarto quartil da relação cintura-estatura na linha de base, mesmo após ajuste multivariado por idade, tabagismo, pressão arterial sistólica, colesterol total e hemoglobina glicada. Além disso, neste mesmo estudo, a análise da curva ROC mostrou valores de 0,605; 0,596 e 0,578 respectivamente para relação cintura-estatura, índice de massa corporal e circunferência da cintura com a progressão de $\mathrm{CAC}$, com melhor desempenho da $\mathrm{RCE}$ em relação às outras medidas de obesidade (Oh et al., 2016).

Comparado aos estudos anteriores, o presente estudo apresenta um número maior de homens e de mulheres, com uma amostra mais velha do que a amostra de Oh et al., porém mais jovem do que a de Kramer et al. Esta análise também apresenta uma heterogeneidade étnica maior em comparação a dos outros dois estudos realizados na Irlanda (Kramer et al.) e na Coréia do Sul (Oh et al.), sendo que o estudo coreano só incluiu homens. Apesar das diferenças de desenho (transversal vs. prospectivo), número de participantes (maior no ELSA-Brasil em relação aos dois estudos internacionais) e idade média entre os três estudos, mais elevada no estudo de Kramer, seguido pelo ELSABrasil e pelo Kangbuk Samsung Health Study, todos os rês resultados mostram uma 
associação positiva entre a relação cintura-estatura e CAC, com o aumento dos valores de relação cintura-estatura se associando com a presença ou progressão de CAC nos dois estudos prospectivos.

Há mais estudos publicados avaliando a associação entre a RCE com a EIMC (Maher et al, 2009; Heidari-Beni et al., 2012; Recio-Rodriguez et al., 2012) do que em relação ao CAC.

Todos os estudos mostraram associação positiva entre RCE e EIMC utilizando metodologias diferentes. Maher et al., em um estudo transversal envolvendo 100 indivíduos saudáveis (29 homens e 71 mulheres) com idade média de 41 anos, observaram a correlação entre medidas de obesidade (índice de massa corporal, circunferência da cintura, relação cintura-quadril e relação cintura-estatura) com medidas vasculares (espessura intima média da carótida, avaliação da rigidez vascular e testes de reatividade da artéria braquial). $\mathrm{O}$ ponto de corte da $\mathrm{RCE} \geq 0,5$ diferenciou os participantes com fatores de risco vasculares e metabólicos daqueles sem alterações clínicas. Outras medidas antropométricas como IMC $\geq 25 \mathrm{~kg} / \mathrm{m}^{2}$, circunferência da cintura (cortada em homens $\geq 102 \mathrm{~cm}$ e em mulheres $\geq 88 \mathrm{~cm}$ e relação cintura-quadril (cortada em $\geq 0,9$ para homens e $\geq 0,8$ para mulheres) também foram capazes de diferenciar indivíduos com alterações metabólicas dos sem alterações metabólicas. A $\mathrm{RCE} \geq 0,5$ se mostrou tão confiável quanto o $\mathrm{IMC} \geq 25 \mathrm{~kg} / \mathrm{m}^{2}$ na determinação das alterações vasculares e metabólicas com elevada correlação entre as duas medidas (89\%, p <0,0001) (MAHER et al., 2009). Em análise prévia no ELSA-Brasil, a RCE $\geq 0,5$ mostrou poder de discriminação para identificação de alterações cardiometabólicas (Castanheira et al., 2018).

Outro estudo transversal realizado na Espanha por Recio-Rodrigues et al., com 305 indivíduos (163 homens e 142 mulheres, idade média de 53 anos), observou a relação 
da obesidade abdominal medida pela $\mathrm{CC}$ e pela RCE, da obesidade geral medida pelo IMC e da porcentagem de gordura corporal (\%GC), com parâmetros que medem a aterosclerose subclínica (EIMC) e a velocidade da onda de pulso das artérias carótida e femoral em indivíduos saudáveis, diabéticos e hipertensos. Os resultados mostraram que medidas de obesidade abdominal (RCE e CC) se correlacionam melhor que IMC e \%GC com medidas de rigidez arterial e EIMC. Especificamente para a EIMC observaram-se valores de correlação de RCE, CC, IMC e \%GC de 0,877;0,858;0,538;0,506, respectivamente. Além disso, o estudo ainda mostrou uma associação positiva da RCE com EIMC após análise de regressão multivariada incluindo vários fatores de confusão, IMC e circunferência da cintura, demonstrando que a cada 0,1 ponto de aumento na RCE houve o aumento de 0,001 mm na EIMC (Recio-Rodrigues et al., 2012).

Em estudo envolvendo 100 mulheres adultas, Heidari-Beni et al., avaliaram os indicadores antropométricos de obesidade (CC, RCQ, RCE, IMC e \% GC) e sua associação com a aterosclerose mensurada pela EIMC, usando a correlação de Pearson e curva ROC. O estudo definiu como risco uma EIMC aumentada os valores $>0,8 \mathrm{~mm}$ e normal como EIMC $\leq 0,8 \mathrm{~mm}$. Dentre os índices avaliados, a RCE $(\mathrm{r}=0,39, \mathrm{p}<0.001)$ mostrou a correlação mais forte com a EIMC e a RCQ $(r=0,27, p<0,006)$ a mais fraca. A curva ROC mostrou um desempenho melhor da RCE e do IMC frente a outras medidas antropométricas (ambos, AUC $=0,74$ ) comparadas com os outros índices como a CC, \%GC e RCQ (AUC=0,73; 0,69; e 0,68; respectivamente) (HeidariI-Beni et al., 2012). O valor de ponto de corte para RCE no estudo de Heidari-Beni et al., obtido pela análise da curva ROC foi de 0,64 . Esse valor foi diferente do valor encontrado m outros estudos incluindo o próprio ELSA-Brasil que tem sugerido valor acima de 0,5 como um indicador de aumento de risco à saúde (Browning et al., 2010; Ashwell et al., 2014). 
Outros três estudos com metodologia mais semelhante à utilizada nesta análise avaliaram a associação da RCE com a EIMC (Ge et al., 2014; Ren et al., 2014; Zhang et al., 2014), também com resultados positivos.

Ge et al., avaliaram em 562 indivíduos de uma população rural de Bangladesh (205 homens e 357 mulheres) com idade média de 40 anos, a associação de diferentes medidas antropométricas como RCQ, RCE, CC, além da circunferência do braço e da coxa com a EIMC. A RCE e CC mostraram associação positiva e significativa com a EIMC, onde por meio de regressão linear com ajuste multivariado demonstrou que a cada aumento do desvio padrão de $\operatorname{RCE}(0,07)$ e de RCQ $(0,08)$ houve associação com 8,96 $\mu \mathrm{m}(\mathrm{IC} 95 \%$ 1,12-16,81) e com 11,45 $\mu \mathrm{m}$ (IC 95\% 0,86-22,04) na EIMC após ajuste para idade, sexo, IMC, tabagismo, nível de escolaridade e pressão arterial sistólica (Ge et al., 2014).

Ren et al., avaliaram a associação entre a RCE e EIMC em 3381 indivíduos de uma população saudável da China (1362 homens e 2019 mulheres), com média de idade em torno de 40 anos. Na análise de regressão logística, Ren et al., demonstraram a associação positiva da RCE >0,5 com valores elevados de EIMC (>0,7 mm) com uma razão de chance de 1,45 (IC95\%: 1,14-1,83) após ajuste para fatores de risco cardiovasculares, demonstrando também que a cada aumento de 1 unidade na RCE ocorre uma razão de chances de 1,24 (95\% CI: 1,12-1,37) na EIMC, ajustado para fatores de risco cardiovascular (Ren et al., 2014).

O presente estudo demonstra através da regressão linear, associação positiva da RCE com EIMC quando ajustado para fatores socioeconômicos e riscos cardiovasculares, onde para cada aumento de 1 unidade da RCE ocorre aumento de 0,22 mm na EIMC (IC95\% CI: 0,17-0,27). 
Em análise com 2063 mulheres e 814 homens saudáveis, com idade média em torno de 57 anos, na China, Zhang et al., também estudou-se a associação de índices antropométricos e de gordura corporal (IMC, CC, RCE, RCQ, \%GC) com a EIMC. Após regressão logística houve associação positiva da RCE com a EIMC tanto para homens quanto para mulheres (respectivamente, 1,71; IC 95\%, 1,41-2,08 e 1,36; IC95\% 1,171,59) ajustados para idade, nível educacional, tabagismo, consumo de álcool e prática de atividade física (Zhang et al., 2014)

Em comparação com esses estudos anteriores com resultados positivos, esta análise demonstra uma associação entre a RCE e a EIMC usando modelos logísticos e lineares ajustados por fatores sociodemográficos e de risco cardiovasculares. Nosso estudo apresenta algumas diferenças em relação a esses outros estudos. Nosso tamanho da amostra (4.261) é maior e com uma proporção semelhante de homens e mulheres em comparação com estudos anteriores. A média de idade nesta amostra em torno de 50 anos é intermediária, maior do que os estudos de Ge e Ren et al., mas menor que o estudo de Zhang et al. A amostra do presente estudo também apresenta heterogeneidade étnica maior em relação as amostras dos outros estudos comparada a de outro estudos provenientes da Irlanda (Maher et al., 2009), Espanha (Recio-Rodrigues et al., 2012), Irã (Heidari-Beni et al., 2012), Bangladesh (Ge et al., 2014) e China (Ren et al., 2014; Zhang et al., 2014). Além disso, somente os estudos feitos na China e em Blangadesh têm uma base comunitária. Os outros estudos incluíram amostras menores e de conveniência. Entretanto, apesar de todas essas diferenças, os resultados desta análise são similares aos já publicados, confirmando a RCE como um marcador de aterosclerose subclínica em um país de baixa e média renda com grande heterogeneidade étnica. 
A relação entre adiposidade abdominal e a aterosclerose subclínica também está possivelmente vinculada ao componente visceral da gordura abdominal (Eickemberg et al., 2018).

Há vários fatores relacionados à obesidade, especialmente a obesidade abdominal que podem explicar a associação das medidas antropométricas com alterações vasculares e metabólicas como níveis séricos de angiotensina II, por exemplo, e de adipocinas pró inflamatórias, como a relação leptina-adiponectina, podendo a leptina ser uma das forças motrizes para o espessamento da íntima-média (Norata et.al, 2007; Maher et al., 2009).

No presente estudo a associação entre RCE e CAC foi positiva nos homens, mas não nas mulheres. As mulheres possuem mais gordura corporal total (e subcutânea) frequentemente nas pernas e glúteos. Já os homens tendem a acumular gordura na região abdominal ao longo da vida, por isso apresentam maior risco para desenvolver desfechos cardiovasculares, inclusive aterosclerose (Palmer et al., 2015).

Porém no estudo, tanto homens e mulheres apresentaram associação positiva da RCE com EIMC.

Esses resultados diferentes para CAC e EIMC podem ser devido a diferentes estágios da aterosclerose subclínica. O EIMC reflete os primeiros estágios enquanto o CAC reflete estágios posteriores do processo aterosclerótico. Mais do que isso, um alto valor de EIMC poderia refletir não apenas o espessamento da camada íntima, mas também a hipertrofia da camada média (Touboul et al.,2011). Essas diferenças podem explicar, pelo menos parcialmente, essa associação heterogênea entre a relação cinturaestatura com doença aterosclerótica.

A RCE apresenta vantagens e desvantagens. Seu cálculo resulta da mensuração de duas medidas (altura e cintura) que devem ser cuidadosamente realizadas. A RCE, porém, apresenta algumas vantagens como medida antropométrica, pois há um ponto de 
corte que pode ser usado para homens, mulheres, crianças e adultos de todos os grupos étnicos (Ashwell et al., 2005; Correa et al., 2016; Lo et al., 2016). Esta é uma vantagem importante, pois evita pontos de corte diferenciados por sexo e raça como a medida da CC, por exemplo.

O presente estudo é uma análise transversal. Embora a RCE tenha sido associada ao aumento do CAC na linha de base, ressalta-se que análises futuras prospectivas no ELSA-Brasil podem avaliar a associação desta medida com a progressão do CAC e também com a progressão da EIMC. A prevalência de aterosclerose subclínica medida pelo CAC e pela EIMC foi baixa provavelmente devido à idade média da amostra ainda jovem pela inclusão de um grupo de participantes com idades de 35 a 44 anos. É uma amostra de funcionários públicos com características diferentes da população geral o que poderia comprometer a generalização dos resultados. Entretanto, é uma amostra muito semelhante à encontrada nas áreas metropolitanas das grandes cidades do Brasil como pode se observar na semelhança de alguns resultados do ELSA-Brasil com os do VIGITEL em aferições que foram mensuradas de forma semelhante. 


\section{CONCLUSÕES}

Nesta análise transversal observou-se uma associação entre a relação cinturaestatura (RCE) e o escore de cálcio coronariano (CAC) e EIMC após ajuste multivariado por fatores de confusão mostrando-se um bom marcador de aterosclerose subclínica na amostra.

$\mathrm{Na}$ amostra geral, nos quintis mais elevados de RCE, encontra-se uma menor frequência de brancos e de indivíduos com ensino superior completo, uma maior presença de fatores de risco cardiovascular além de valores maiores de EIMC $\geq$ P75 bem como uma frequência mais elevada de indivíduos com $\mathrm{CAC}>0$ e $\mathrm{CAC} \geq 100$.

Nos quintis mais altos da RCE homens e mulheres apresentam as maiores médias de idade, porém com maior número de homens brancos e de homens com maior renda familiar mensal média. Entre as mulheres ocorre uma menor frequência de ensino superior completo e menor renda familiar mensal média. Tanto os homens quantos as mulheres nos maiores quintis da RCE apresentam um perfil de fatores de risco cardiovasculares menos saudáveis, além de valores maiores de EIMC $\geq$ P75 e frequência mais elevada de $\mathrm{CAC}>0$ e de $\mathrm{CAC} \geq 100$.

A associação da RCE com o CAC foi significativa para CAC acima de zero, mas não para o $\mathrm{CAC} \geq 100$ nos homens quando ajustado por fatores de risco sociodemográficos e cardiovasculares. Nas mulheres não houve associação da medida da RCE com CAC.

A RCE mostrou associação positiva com a EIMC nos modelos ajustados por variáveis sociodemográficas e por fatores de risco cardiovasculares tanto nos homens quanto nas mulheres. 


\section{REFERÊNCIAS}

Afshin A, Forouzanfar MH, Reitsma MB, Sur P, Estep K, Lee A, et al. Health Effects of Overweight and Obesity in 195 Countries over 25 Years. N Engl J Med. 2017;377(1):1327.

Agatston AS, Janowitz WR, Hildner FJ, Zusmer NR, Viamonte M, Jr., Detrano R. Quantification of coronary artery calcium using ultrafast computed tomography. J Am Coll Cardiol. 1990;15(4):827-32.

Almeida RTd, Almeida MMGd, Araújo TM. Obesidade abdominal e risco cardiovascular: desempenho de indicadores antropométricos em mulheres. Arquivos Brasileiros de Cardiologia. 2009;92:375-80.

Aquino EM, Barreto SM, Bensenor IM, Carvalho MS, Chor D, Duncan BB, et al. Brazilian Longitudinal Study of Adult Health (ELSA-Brasil): objectives and design. Am J Epidemiol. 2012;175(4):315-24.

Ashwell M, Cole TJ, Dixon AK. Ratio of waist circumference to height is strong predictor of intra-abdominal fat. Bmj. 1996;313(7056):559-60.

Ashwell M, Gibson S. A proposal for a primary screening tool: 'Keep your waist circumference to less than half your height'. BMC Med. 2014;12:207.

Ashwell M, Gibson S. Waist-to-height ratio as an indicator of 'early health risk': simpler and more predictive than using a 'matrix' based on BMI and waist circumference. BMJ Open. 2016;6(3):e010159.

Ashwell M, Gunn P, Gibson S. Waist-to-height ratio is a better screening tool than waist circumference and BMI for adult cardiometabolic risk factors: systematic review and meta-analysis. Obes Rev. 2012;13(3):275-86.

Ashwell M, Hsieh SD. Six reasons why the waist-to-height ratio is a rapid and effective global indicator for health risks of obesity and how its use could simplify the international public health message on obesity. Int J Food Sci Nutr. 2005;56(5):303-7.

Ashwell M, Lejeune S, McPherson K. Ratio of waist circumference to height may be better indicator of need for weight management. Bmj. 1996;312(7027):377.

Baena CP, Lotufo PA, Santos IS, Goulart AC, Bittencourt MS, Duncan BB, et al. Neck circumference is associated with carotid intimal-media thickness but not with coronary artery calcium: Results from The ELSA-Brasil. Nutr Metab Cardiovasc Dis. 2016;26(3):216-22.

Barroso TA, Marins LB, Alves R, Gonçalves ACS, Barroso SG, Rocha GdS. Association of Central Obesity with The Incidence of Cardiovascular Diseases and Risk Factors. International Journal of Cardiovascular Sciences. 2017;30:416-24. 
Bensenor IM, Goulart AC, Santos IS, Bittencourt MS, Pereira AC, Santos RD, et al. Association between a healthy cardiovascular risk factor profile and coronary artery calcium score: Results from the Brazilian Longitudinal Study of Adult Health (ELSABrasil). Am Heart J. 2016;174:51-9.

Bensenor IM, Griep RH, Pinto KA, Faria CP, Felisbino-Mendes M, Caetano EI, et al. [Routines of organization of clinical tests and interviews in the ELSA-Brasil investigation center]. Rev Saude Publica. 2013;47 Suppl 2:37-47.

Brant LCC, Nascimento BR, Passos VMA, Duncan BB, Bensenor IJM, Malta DC, et al. Variations and particularities in cardiovascular disease mortality in Brazil and Brazilian states in 1990 and 2015: estimates from the Global Burden of Disease. Rev Bras Epidemiol. 2017;20Suppl 01(Suppl 01):116-28.

Brasil. Ministério da Saúde. Secretaria de Vigilância em Saúde. Departamento de Vigilância de Doenças e Agravos não Transmissíveis e Promoção da S. Vigitel Brasil 2018: vigilância de fatores de risco e proteção para doenças crônicas por inquérito telefônico: estimativas sobre frequência e distribuição sociodemográfica de fatores de risco e proteção para doenças crônicas nas capitais dos 26 estados brasileiros e no Distrito Federal em 2018. 2019:132.

Browning LM, Hsieh SD, Ashwell M. A systematic review of waist-to-height ratio as a screening tool for the prediction of cardiovascular disease and diabetes: 0.5 could be a suitable global boundary value. Nutr Res Rev. 2010;23(2):247-69.

Budoff MJ, Achenbach S, Blumenthal RS, Carr JJ, Goldin JG, Greenland P, et al. Assessment of coronary artery disease by cardiac computed tomography: a scientific statement from the American Heart Association Committee on Cardiovascular Imaging and Intervention, Council on Cardiovascular Radiology and Intervention, and Committee on Cardiac Imaging, Council on Clinical Cardiology. Circulation. 2006;114(16):1761-91.

Budoff MJ, Diamond GA, Raggi P, Arad Y, Guerci AD, Callister TQ, et al. Continuous probabilistic prediction of angiographically significant coronary artery disease using electron beam tomography. Circulation. 2002;105(15):1791-6.

Burden of disease in Brazil, 1990-2016: a systematic subnational analysis for the Global Burden of Disease Study 2016. Lancet. 2018;392(10149):760-75.

Caspard H, Jabbour S, Hammar N, Fenici P, Sheehan JJ, Kosiborod M. Recent trends in the prevalence of type 2 diabetes and the association with abdominal obesity lead to growing health disparities in the USA: An analysis of the NHANES surveys from 1999 to 2014. Diabetes Obes Metab. 2018;20(3):667-71.

Cassidy AE, Bielak LF, Zhou Y, Sheedy PF, 2nd, Turner ST, Breen JF, et al. Progression of subclinical coronary atherosclerosis: does obesity make a difference? Circulation. 2005;111(15):1877-82. 
Castanheira M, Chor D, Braga JU, Cardoso LO, Griep RH, Molina M, et al. Predicting cardiometabolic disturbances from waist-to-height ratio: findings from the Brazilian Longitudinal Study of Adult Health (ELSA-Brasil) baseline. Public Health Nutr. 2018;21(6):1028-35.

Christen T, Trompet S, Rensen PCN, Willems van Dijk K, Lamb HJ, Jukema JW, et al. The role of inflammation in the association between overall and visceral adiposity and subclinical atherosclerosis. Nutr Metab Cardiovasc Dis. 2019;29(7):728-35.

Correa MM, Thume E, De Oliveira ER, Tomasi E. Performance of the waist-to-height ratio in identifying obesity and predicting non-communicable diseases in the elderly population: A systematic literature review. Arch Gerontol Geriatr. 2016;65:174-82.

Cox BD, Whichelow M. Ratio of waist circumference to height is better predictor of death than body mass index. Bmj. 1996;313(7070):1487.

Dahlen EM, Lanne T, Engvall J, Lindstrom T, Grodzinsky E, Nystrom FH, et al. Carotid intima-media thickness and apolipoprotein B/apolipoprotein A-I ratio in middle-aged patients with Type 2 diabetes. Diabet Med. 2009;26(4):384-90.

De Michele M, Panico S, Iannuzzi A, Celentano E, Ciardullo AV, Galasso R, et al. Association of obesity and central fat distribution with carotid artery wall thickening in middle-aged women. Stroke. 2002;33(12):2923-8.

Detrano R, Guerci AD, Carr JJ, Bild DE, Burke G, Folsom AR, et al. Coronary calcium as a predictor of coronary events in four racial or ethnic groups. $\mathrm{N}$ Engl $\mathrm{J}$ Med. 2008;358(13):1336-45.

Eickemberg M, Amorim L, Almeida M, Aquino EML, Fonseca M, Santos IS, et al. Indicators of Abdominal Adiposity and Carotid Intima-Media Thickness: Results from the Longitudinal Study of Adult Health (ELSA-Brazil). Arq Bras Cardiol. 2019;112(3):220-7.

Erbel R, Mohlenkamp S, Moebus S, Schmermund A, Lehmann N, Stang A, et al. Coronary risk stratification, discrimination, and reclassification improvement based on quantification of subclinical coronary atherosclerosis: the Heinz Nixdorf Recall study. J Am Coll Cardiol. 2010;56(17):1397-406.

Fedeli LG, Vidigal PG, Leite CM, Castilhos CD, Pimentel RA, Maniero VC, et al. [Logistics of collection and transportation of biological samples and the organization of the central laboratory in the ELSA-Brasil]. Rev Saude Publica. 2013;47 Suppl 2:63-71.

Folsom AR, Kronmal RA, Detrano RC, O'Leary DH, Bild DE, Bluemke DA, et al. Coronary artery calcification compared with carotid intima-media thickness in the prediction of cardiovascular disease incidence: the Multi-Ethnic Study of Atherosclerosis (MESA). Arch Intern Med. 2008;168(12):1333-9.

Fuster JJ, Ouchi N, Gokce N, Walsh K. Obesity-Induced Changes in Adipose Tissue Microenvironment and Their Impact on Cardiovascular Disease. Circ Res. 2016;118(11):1786-807. 
Gao W, Qiao X, Wang Y, Wan L, Wang Z, Wang X, et al. The Interactive Association of General Obesity and Central Obesity with Prevalent Hypertension in Rural Lanzhou, China. PLoS One. 2016;11(10):e0164409.

Garn SM, Leonard WR, Hawthorne VM. Three limitations of the body mass index. Am J Clin Nutr. 1986;44(6):996-7.

Ge W, Parvez F, Wu F, Islam T, Ahmed A, Shaheen I, et al. Association between anthropometric measures of obesity and subclinical atherosclerosis in Bangladesh. Atherosclerosis. 2014;232(1):234-41.

Global, regional, and national age-sex-specific mortality and life expectancy, 1950-2017: a systematic analysis for the Global Burden of Disease Study 2017. Lancet. 2018;392(10159):1684-735.

Global, regional, and national age-sex-specific mortality for 282 causes of death in 195 countries and territories, 1980-2017: a systematic analysis for the Global Burden of Disease Study 2017. Lancet. 2018;392(10159):1736-88.

Grobbee DE, Bots ML. Carotid artery intima-media thickness as an indicator of generalized atherosclerosis. J Intern Med. 1994;236(5):567-73.

Haun DR, Pitanga FJG, lessa I. Razão cintura/estatura comparado a outros indicadores antropométricos de obesidade como preditor de risco coronariano elevado. Revista da Associação Médica Brasileira. 2009;55:705-11.

Heidari-Beni M, Hajimaghsood M, Ebrahimi-Mamaghani M, Jafarabadi MA, MousaviJazayeri SM, Mohtadinia J. Diagnostic value of anthropometric indices for initial stage of atherosclerosis in adult women. Asia Pac J Clin Nutr. 2012;21(2):220-6.

Hotamisligil GS, Shargill NS, Spiegelman BM. Adipose expression of tumor necrosis factor-alpha: direct role in obesity-linked insulin resistance. Science. 1993;259(5091):8791.

Hsieh SD, Yoshinaga H. Abdominal fat distribution and coronary heart disease risk factors in men-waist/height ratio as a simple and useful predictor. Int J Obes Relat Metab Disord. 1995;19(8):585-9.

Hsieh SD, Yoshinaga $\mathrm{H}$. Waist/height ratio as a simple and useful predictor of coronary heart disease risk factors in women. Intern Med. 1995;34(12):1147-52.

Hunt JL, Fairman R, Mitchell ME, Carpenter JP, Golden M, Khalapyan T, et al. Bone formation in carotid plaques: a clinicopathological study. Stroke. 2002;33(5):1214-9.

Instituto Brasileiro de Geografia e Estatística. Pesquisa de orçamentos familiares 20082009: antropometria e estado nutricional de crianças, adolescentes e adultos no Brasil. Rio de Janeiro: IBGE; 2010. 
Kramer CK, von Muhlen D, Gross JL, Barrett-Connor E. A prospective study of abdominal obesity and coronary artery calcium progression in older adults. J Clin Endocrinol Metab. 2009;94(12):5039-44.

Lakka TA, Lakka HM, Salonen R, Kaplan GA, Salonen JT. Abdominal obesity is associated with accelerated progression of carotid atherosclerosis in men. Atherosclerosis. 2001;154(2):497-504.

Larsson B, Svardsudd K, Welin L, Wilhelmsen L, Bjorntorp P, Tibblin G. Abdominal adipose tissue distribution, obesity, and risk of cardiovascular disease and death: 13 year follow up of participants in the study of men born in 1913. Br Med J (Clin Res Ed). 1984;288(6428):1401-4.

Lean ME, Han TS, Morrison CE. Waist circumference as a measure for indicating need for weight management. Bmj. 1995;311(6998):158-61.

Lee CM, Huxley RR, Wildman RP, Woodward M. Indices of abdominal obesity are better discriminators of cardiovascular risk factors than BMI: a meta-analysis. J Clin Epidemiol. 2008;61(7):646-53.

Lee JS, Aoki K, Kawakubo K, Gunji A. A study on indices of body fat distribution for screening for obesity. Sangyo Eiseigaku Zasshi. 1995;37(1):9-18.

Lee SW, Son JY, Kim JM, Hwang SS, Han JS, Heo NJ. Body fat distribution is more predictive of all-cause mortality than overall adiposity. Diabetes Obes Metab. 2018;20(1):141-7.

Lima C, Basile L, Silveira J, Vieira P, Oliveira M. CIRCUNFERÊNCIA DA CINTURA OU ABDOMINAL? UMA REVISÃO CRÍTICA DOS REFERENCIAIS METODOLÓGICOS. Revista Simbio-Logias. 2011;4:108-31.

Lo K, Wong M, Khalechelvam P, Tam W. Waist-to-height ratio, body mass index and waist circumference for screening paediatric cardio-metabolic risk factors: a metaanalysis. Obes Rev. 2016;17(12):1258-75.

Lohman TG, Roche AF, Martorell R. Anthropometric standardization reference manual. Champaign, IL: Human Kinetics Books; 1988.

Lotufo PA. Cardiovascular diseases in Brazil: premature mortality, risk factors and priorities for action. Comments on the preliminary results from the Brazilian National Health Survey (PNS), 2013. Sao Paulo Med J. 2015;133(2):69-72.

Maher V, O'Dowd M, Carey M, Markham C, Byrne A, Hand E, et al. Association of central obesity with early Carotid intima-media thickening is independent of that from other risk factors. Int J Obes (Lond). 2009;33(1):136-43.

Malta DC, Silva Jr JBd. O Plano de Ações Estratégicas para o Enfrentamento das Doenças Crônicas Não Transmissíveis no Brasil e a definição das metas globais para o enfrentamento dessas doenças até 2025: uma revisão. Epidemiologia e Serviços de Saúde. 2013;22:151-64. 
Mandviwala T, Khalid U, Deswal A. Obesity and Cardiovascular Disease: a Risk Factor or a Risk Marker? Curr Atheroscler Rep. 2016;18(5):21.

Mill JG, Pinto K, Griep RH, Goulart A, Foppa M, Lotufo PA, et al. [Medical assessments and measurements in ELSA-Brasil]. Rev Saude Publica. 2013;47 Suppl 2:54-62.

National Health and Nutrition Examination Survey. Anthropometry Procedures Manual. Atlanta: Centers for Disease Control and Prevation; 2004.

Neeland IJ, Poirier P, Despres JP. Cardiovascular and Metabolic Heterogeneity of Obesity: Clinical Challenges and Implications for Management. Circulation. 2018;137(13):1391-406.

Neves PO, Andrade J, Moncao H. Coronary artery calcium score: current status. Radiol Bras. 2017;50(3):182-9.

Norata GD, Raselli S, Grigore L, Garlaschelli K, Dozio E, Magni P, et al. Leptin:adiponectin ratio is an independent predictor of intima media thickness of the common carotid artery. Stroke. 2007;38(10):2844-6.

Nurdiantami Y, Watanabe K, Tanaka E, Pradono J, Anme T. Association of general and central obesity with hypertension. Clin Nutr. 2018;37(4):1259-63.

Oh HG, Nallamshetty S, Rhee EJ. Increased Risk of Progression of Coronary Artery Calcification in Male Subjects with High Baseline Waist-to-Height Ratio: The Kangbuk Samsung Health Study. Diabetes Metab J. 2016;40(1):54-61.

Oliveira LS, Rodrigues PAS. Circunferência de cintura: protocolos de mensuração e sua aplicabilidade prática. Revista de Nutrição e Vigilância em Saúde. 2016;3(2):90-5.

Oliveira MAM, Fagundes RLM, Moreira EAM, Trindade EBSdM, Carvalho Td. Relação de indicadores antropométricos com fatores de risco para doença cardiovascular. Arquivos Brasileiros de Cardiologia. 2010;94:478-85.

Palmer BF, Clegg DJ. The sexual dimorphism of obesity. Mol Cell Endocrinol. 2015;402:113-9.

Parikh RM, Joshi SR, Menon PS, Shah NS. Index of central obesity - A novel parameter. Med Hypotheses. 2007;68(6):1272-5.

Petersson H, Daryani A, Riserus U. Sagittal abdominal diameter as a marker of inflammation and insulin resistance among immigrant women from the Middle East and native Swedish women: a cross-sectional study. Cardiovasc Diabetol. 2007;6:10.

Piche ME, Poirier P, Lemieux I, Despres JP. Overview of Epidemiology and Contribution of Obesity and Body Fat Distribution to Cardiovascular Disease: An Update. Prog Cardiovasc Dis. 2018;61(2):103-13. 
Pinho CPS, Diniz ADS, Arruda IKG, Leite A, Petribu MMV, Rodrigues IG. Waist circumference measurement sites and their association with visceral and subcutaneous fat and cardiometabolic abnormalities. Arch Endocrinol Metab. 2018;62(4):416-23.

Pitanga FJG, Lessa I. Indicadores antropométricos de obesidade como instrumento de triagem para risco coronariano elevado em adultos na cidade de Salvador - Bahia. Arquivos Brasileiros de Cardiologia. 2005;85:26-31.

Pitanga FJG. Antropometria na avaliação da obesidade abdominal e risco coronariano. Revista Brasileira de Cineantropometria \& Desempenho Humano. 2011;13:238-41.

Pouliot MC, Despres JP, Lemieux S, Moorjani S, Bouchard C, Tremblay A, et al. Waist circumference and abdominal sagittal diameter: best simple anthropometric indexes of abdominal visceral adipose tissue accumulation and related cardiovascular risk in men and women. Am J Cardiol. 1994;73(7):460-8.

Raggi P, Callister TQ, Cooil B, He ZX, Lippolis NJ, Russo DJ, et al. Identification of patients at increased risk of first unheralded acute myocardial infarction by electron-beam computed tomography. Circulation. 2000;101(8):850-5.

Rangel-Baltazar E, Cuevas-Nasu L, Shamah-Levy T, Rodriguez-Ramirez S, MendezGomez-Humaran I, Rivera JA. Association between High Waist-to-Height Ratio and Cardiovascular Risk among Adults Sampled by the 2016 Half-Way National Health and Nutrition Survey in Mexico (ENSANUT MC 2016). Nutrients. 2019;11(6).

Recio-Rodriguez JI, Gomez-Marcos MA, Patino-Alonso MC, Agudo-Conde C, Rodriguez-Sanchez E, Garcia-Ortiz L. Abdominal obesity vs general obesity for identifying arterial stiffness, subclinical atherosclerosis and wave reflection in healthy, diabetics and hypertensive. BMC Cardiovasc Disord. 2012;12:3.

Ren C, Zhang J, Xu Y, Xu B, Sun W, Sun J, et al. Association between carotid intimamedia thickness and index of central fat distribution in middle-aged and elderly Chinese. Cardiovasc Diabetol. 2014;13:139.

Ribeiro AL, Duncan BB, Brant LC, Lotufo PA, Mill JG, Barreto SM. Cardiovascular Health in Brazil: Trends and Perspectives. Circulation. 2016;133(4):422-33.

Rodrigues SL, Baldo MP, Mill JG. Association of waist-stature ratio with hypertension and metabolic syndrome: population-based study. Arq Bras Cardiol. 2010;95(2):186-91.

Roriz C, Karla A, Passos S. et al. Anthropometric clinical indicators in the assessmente of visceral obesity: na update. Nutr clín diet hosp. 2016;36(2):168-79.

Rosvall M, Persson M, Ostling G, Nilsson PM, Melander O, Hedblad B, et al. Risk factors for the progression of carotid intima-media thickness over a 16-year follow-up period: the Malmo Diet and Cancer Study. Atherosclerosis. 2015;239(2):615-21.

Sampaio LR, Simoes EJ, Assis AM, Ramos LR. Validity and reliability of the sagittal abdominal diameter as a predictor of visceral abdominal fat. Arq Bras Endocrinol Metabol. 2007;51(6):980-6. 
Sangros FJ, Torrecilla J, Giraldez-Garcia C, Carrillo L, Mancera J, Mur T, et al. Association of General and Abdominal Obesity With Hypertension, Dyslipidemia and Prediabetes in the PREDAPS Study. Rev Esp Cardiol (Engl Ed). 2018;71(3):170-7.

Santos IS, Alencar AP, Rundek T, Goulart AC, Barreto SM, Pereira AC, et al. Low Impact of Traditional Risk Factors on Carotid Intima-Media Thickness: The ELSA-Brasil Cohort. Arterioscler Thromb Vasc Biol. 2015;35(9):2054-9.

Santos IS, Bittencourt MS, Oliveira IR, Souza AG, Meireles DP, Rundek T, et al. Carotid intima-media thickness value distributions in the Brazilian Longitudinal Study of Adult Health (ELSA-Brasil). Atherosclerosis. 2014;237(1):227-35.

Schetz MA-O, De Jong A, Deane AM, Druml W, Hemelaar P, Pelosi P, et al. Obesity in the critically ill: a narrative review. Intensive Care Med. 2019;45(6):757-69.

Schmidt MI, Duncan BB, Mill JG, Lotufo PA, Chor D, Barreto SM, et al. Cohort Profile: Longitudinal Study of Adult Health (ELSA-Brasil). Int J Epidemiol. 2015;44(1):68-75.

Segura-Fragoso A, Rodriguez-Padial L, Alonso-Moreno FJ, Villarin-Castro A, RojasMartelo GA, Rodriguez-Roca GC, et al. Anthropometric measurements of general and central obesity and discriminative capacity on cardiovascular risk: RICARTO study. Semergen. 2019;45(5):323-32.

Seidell JC, Perusse L, Despres JP, Bouchard C. Waist and hip circumferences have independent and opposite effects on cardiovascular disease risk factors: the Quebec Family Study. Am J Clin Nutr. 2001;74(3):315-21.

Shuster A, Patlas M, Pinthus JH, Mourtzakis M. The clinical importance of visceral adiposity: a critical review of methods for visceral adipose tissue analysis. Br J Radiol. 2012;85(1009):1-10.

Sippel C, Bastianb RMA, Sippel C, Giovanella J, et al. Processos inflamatórios de obesidade. Revista de Atenção à Saúde. 2014;12(42):48-56.

Tongdee P, Annanon N, Wattanapan P, Loyd R, Nimkuntod P. Waist/Height Ratio and Traditional Anthropometry for Screening Early Atherosclerosis in Premenopausal/Menopausal Women. Journal of Health Research. 2016;30.

Touboul PJ, Hennerici MG, Meairs S, Adams H, Amarenco P, Bornstein N, et al. Mannheim carotid intima-media thickness and plaque consensus (2004-2006-2011). An update on behalf of the advisory board of the 3rd, 4th and 5th watching the risk symposia, at the 13th, 15th and 20th European Stroke Conferences, Mannheim, Germany, 2004, Brussels, Belgium, 2006, and Hamburg, Germany, 2011. Cerebrovasc Dis. 2012;34(4):290-6.

Treff C, Bensenor IM, Lotufo PA. Leisure-time and commuting physical activity and high blood pressure: the Brazilian Longitudinal Study of Adult Health (ELSA-Brasil). J Hum Hypertens. 2017;31(4):278-83. 
Valdez R. A simple model-based index of abdominal adiposity. J Clin Epidemiol. 1991;44(9):955-6.

Wang J, Thornton JC, Bari S, Williamson B, Gallagher D, Heymsfield SB, et al. Comparisons of waist circumferences measured at 4 sites. Am $\mathrm{J}$ Clin Nutr. 2003;77(2):379-84.

World Health Organization. Obesity and overweight. 2018.

World Health Organization. Obesity: preventing and managing the global epidemic. Geneva: WHO; 1998.

World Health Organization. Waist circumference and waist-hip ratio. Geneva: WHO; 2011.Williamson DF, Kahn HS, Worthman CM, Burnette JC, Russell CM. Precision of recumbent anthropometry. Am J Hum Biol. 1993;5(2):159-67.

Yu JH, Yim SH, Yu SH, et al. The relationship of body composition and coronary artery calcification in apparently healthy korean adults. Endocrinol Metab (Seoul). 2013;28(1):33-40.

Yusuf S, Hawken S, Ounpuu S, Dans T, Avezum A, Lanas F, et al. Effect of potentially modifiable risk factors associated with myocardial infarction in 52 countries (the INTERHEART study): case-control study. Lancet. 2004;364(9438):937-52.

Zhang ZQ, He LP, Xie XY, Ling WH, Deng J, Su YX, et al. Association of simple anthropometric indices and body fat with early atherosclerosis and lipid profiles in oesyChinese adults. PLoS One. 2014;9(8):e104361. 